\title{
Pseudomonas aeruginosa: resistance to the max
}

\author{
Keith Poole* \\ Department of Microbiology and Immunology, Queen's University, Kingston, ON, Canada
}

Edited by:

Dara Frank, Medical College of

Wisconsin, USA

Reviewed by:

Marcelo Tolmasky, California State

University Fullerton, USA

Linda D. Hazlett, Wayne State

University School of Medicine, USA

Everett Peter Greenberg, University of

Washington, USA

${ }^{*}$ Correspondence:

Keith Poole, Department of

Microbiology and Immunology,

Queen's University, Kingston, ON,

Canada K $7 L$ 3N6.

e-mail:poolek@queensu.ca
Pseudomonas aeruginosa is intrinsically resistant to a variety of antimicrobials and can develop resistance during anti-pseudomonal chemotherapy both of which compromise treatment of infections caused by this organism. Resistance to multiple classes of antimicrobials (multidrug resistance) in particular is increasingly common in $P$. aeruginosa, with a number of reports of pan-resistant isolates treatable with a single agent, colistin. Acquired resistance in this organism is multifactorial and attributable to chromosomal mutations and the acquisition of resistance genes via horizontal gene transfer. Mutational changes impacting resistance include upregulation of multidrug efflux systems to promote antimicrobial expulsion, derepression of ampC, AmpC alterations that expand the enzyme's substrate specificity (i.e., extended-spectrum AmpC), alterations to outer membrane permeability to limit antimicrobial entry and alterations to antimicrobial targets. Acquired mechanisms contributing to resistance in $P$. aeruginosa include $\beta$-lactamases, notably the extended-spectrum $\beta$-lactamases and the carbapenemases that hydrolyze most $\beta$-lactams, aminoglycoside-modifying enzymes, and $16 \mathrm{~S}$ rRNA methylases that provide high-level pan-aminoglycoside resistance. The organism's propensity to grow in vivo as antimicrobial-tolerant biofilms and the occurrence of hypermutator strains that yield antimicrobial resistant mutants at higher frequency also compromise anti-pseudomonal chemotherapy. With limited therapeutic options and increasing resistance will the untreatable $P$. aeruginosa infection soon be upon us?

Keywords: Pseudomonas aeruginosa, antimicrobial, resistance, $\beta$-lactamase, efflux, biofilm, hypermutability

\section{INTRODUCTION}

Pseudomonas aeruginosa is a common nosocomial pathogen (Hidron et al., 2008; Jones et al., 2009; Zhanel et al., 2010) that causes infections with a high mortality rate (Mutlu and Wunderink, 2006; Kerr and Snelling, 2009; Mahar et al., 2010; Lambert et al., 2011). This latter is, in part, attributable to the organism's intrinsically high resistance to many antimicrobials (Poole, 2002) and the development of increased, particularly multidrug resistance in healthcare settings (Rossolini and Mantengoli, 2005; Ferrara, 2006; Giamarellos-Bourboulis et al., 2006; Paterson, 2006; Kerr and Snelling, 2009; Shorr, 2009; Hirsch and Tam, 2010; Kallen et al., 2010; Keen III, et al., 2010), both of which complicate antipseudomonal chemotherapy. Indeed, numerous studies point to a link between multidrug resistance and increased morbidity/ mortality, as well as increased length of hospital stay and increased hospital costs (Slama, 2008; Kerr and Snelling, 2009; Mauldin et al., 2010; Tumbarello et al., 2011). While acquisition of resistance genes [e.g., those encoding $\beta$-lactamases (Gupta, 2008; Zhao and $\mathrm{Hu}, 2010$ ) and aminoglycoside-modifying enzymes (Poole, 2005; Ramirez and Tolmasky, 2010)] via horizontal gene transfer can and do drive antimicrobial/multidrug resistance development in P. aeruginosa (Strateva and Yordanov, 2009), more commonly mutations of chromosomal genes (target site, efflux mutations) explain resistance in this organism (Lister et al., 2009; Strateva and Yordanov, 2009). This review provides an overview of antimicrobial resistance in $P$. aeruginosa that is acquired, either via mutation of endogenous genes or via acquisition of exogenous resistance genes.

\section{RESISTANCE TO $\beta$-LACTAMS}

$\beta$-Lactams, including penicillins (e.g., ticarcillin, piperacillin), cephalosporins (e.g., ceftazidime, cefepime), carbapenems (e.g., imipenem, meropenem), and monobactams (e.g., aztreonam) are commonly used in the treatment of $P$. aeruginosa infections (Paul et al., 2010). Resistance to these agents is increasing (Jones et al., 2009; Zilberberg et al., 2010) and mediated by a variety of mechanisms, most commonly antibiotic cleavage by $\beta$-lactamase enzymes, antibiotic expulsion by chromosomally encoded efflux mechanisms and reduced drug uptake owing to loss of outer membrane porin proteins (Poole, 2004b; Pfeifer et al., 2010).

\section{B-LACTAMASES}

$\beta$-Lactamases, hydrolytic enzymes that disrupt the amide bond of the classical four-membered $\beta$-lactam ring thus rendering the antimicrobial ineffective, are a major determinant of resistance in Gram-negative bacteria, including $P$. aeruginosa. Four molecular classes of these enzymes have been described (A-D) and include metal dependent $\left(\mathrm{Zn}^{2+}\right.$-requiring; class $\left.\mathrm{B}\right)$ and metal-independent (active site serine; classes A, C, and D) $\beta$-lactamases (reviewed in Helfand and Bonomo, 2003), all of which have been reported in $P$. aeruginosa (Zhao and $\mathrm{Hu}, 2010$ ).

\section{Endogenous $\beta$-lactamases}

Pseudomonas aeruginosa typically carries chromosomal genes for two $\beta$-lactamases, a class $\mathrm{C}$ cephalosporinase, AmpC (Lodge et al., 1990), and a class D oxacillinase, PoxB (Girlich et al., 2004; Kong et al., 2005). AmpC is a well-characterized $\beta$-lactamase 
(Jacoby, 2009) commonly linked to $\beta$-lactam resistance in clinical isolates (Arora and Bal, 2005; Bratu et al., 2007; Reinhardt et al., 2007; Tam et al., 2007, 2010; Drissi et al., 2008; Vettoretti et al., 2009; Upadhyay et al., 2010; Xavier et al., 2010) while PoxB activity was only detected in lab mutants lacking AmpC and its clinical significance is uncertain. AmpC, which is a common chromosomally encoded enzyme in many Gram-negative bacteria (Poole, 2004b; Jacoby, 2009), is inducible by a number of $\beta$-lactam antibiotics (e.g., benzyl penicillin and narrow-spectrum cephalosporins) and thus contributes to intrinsic (i.e., natural, non-mutational) resistance to these (Livermore, 1991). It is not, however, inducible by monobactams (aztreonam; Sakurai et al., 1990), the antipseudomonal penicillin piperacillin (Livermore, 1995), and many of the newer cephalosporins (e.g., cefotaxime, ceftriaxone, ceftazidime; Livermore and Yang, 1987; Livermore, 1995; Poole, 2004b) that are, nonetheless, good substrates for the enzyme and as such resistance is dependent upon mutational derepression of ampC. Indeed, mutational derepression of $a m p C$ is the most common mechanism of resistance to $\beta$-lactams in $P$. aeruginosa (Arora and Bal, 2005; Tam et al., 2007; Drissi et al., 2008; Xavier et al., 2010), including expanded-spectrum cephalosporins (e.g., ceftazidime; Juan et al., 2005; Picao et al., 2009a; Queenan et al., 2010) and penicillins (e.g., ticarcillin; Cavallo et al., 2007; Dubois et al., 2008). Interestingly, while carbapenems (e.g., imipenem) are excellent inducers of $a m p C$, their rapid bactericidal activity and stability to hydrolysis renders them effective against $\mathrm{AmpC}^{+} P$. aeruginosa (Jones, 1998) although derepressed AmpC appears to contribute to carbapenem resistance in conjunction with other mechanisms of resistance (e.g., loss of porin protein D; see below). Recently, the production of AmpC variants with improved activity against oxyiminocephalosporins (e.g., ceftazidime), cefepime, and carbapenems (including imipenem), first described in the Enterobacteriacae and referred to as extended-spectrum AmpC (ESAC; Nordmann and Mammeri, 2007), have been reported in clinical isolates of $P$. aeruginosa (Rodriguez-Martinez et al., 2009a,b). These, too, appear to contribute to carbapenem resistance in conjunction with loss of OprD (Rodriguez-Martinez et al., 2009b).

\section{Acquired $\beta$-lactamases}

While the original $\beta$-lactamases were plasmid-encoded restrictedspectrum class A enzymes that only hydrolyzed penicillins and older, narrow-spectrum cephalosporins, more recently described acquired $\beta$-lactamases in $P$. aeruginosa include the extended-spectrum $\beta$-lactamase (ESBL) enzymes (classes A and D) able to hydrolyze a wider range of $\beta$-lactams, including the broad-spectrum cephalosporins and monobactams, and the carbapenemases (classes A, B, and D) that hydrolyze most $\beta$-lactams, including the carbapenems, but not aztreonam (Zhao and $\mathrm{Hu}, 2010$ ). ESBLs and carbapenemases are typically encoded by plasmid- or transposon-bone genes, often on integrons (Poirel and Nordmann, 2002; Castanheira et al., 2004; Walsh et al., 2005; Naas et al., 2006; Bogaerts et al., 2007; Gupta, 2008; Li et al., 2008; Castanheira et al., 2009; Zhao et al., 2009; Kotsakis et al., 2010; Poirel et al., 2010b), genetic elements capable of capturing, and subsequently mobilizing resistance genes (Cambray et al., 2010), although some $\beta$-lactamase genes are associated with novel mobile insertion sequences termed ISCR elements (Poirel et al., 2004; Picao et al., 2009a,b; Kotsakis et al., 2010).
Extended-spectrum $\boldsymbol{\beta}$-lactamases. More commonly reported in the Enterobacteriaceae, though present also in P. aeruginosa, ESBLs typically hydrolyze and, so, provide resistance to broad-spectrum cephalosporins (e.g., the third generation oxyiminocephalosporins cefotaxime and ceftazidime) and aztreonam, in addition to penicillins and narrow-spectrum cephalosporins (reviewed in Paterson and Bonomo, 2005; Bush, 2008). Classical ESBLS have evolved from restricted-spectrum class A TEM and SHV $\beta$-lactamases although a variety of non-TEM, non-SHV class A ESBLS have been described (e.g., CTX-M, PER, VEB, GES, BEL; Poole, 2004b; Paterson and Bonomo, 2005) and class D ESBLs derived from narrow-spectrum OXA $\beta$-lactamases are also well-known (Paterson and Bonomo, 2005; Poirel et al., 2010b).

Class A ESBLs are typically identified in $P$. aeruginosa isolates showing resistance to ceftazidime (e.g., De Champs et al., 2002; Girlich et al., 2002; Strateva et al., 2007; Hocquet et al., 2010].VEBtype ESBLs were the predominant ESBL reported in $P$. aeruginosa in a number of studies where ESBLs were commonly seen (Jiang et al., 2006; Strateva et al., 2007; Woodford et al., 2008; Shahcheraghi et al., 2009) although PER-type ESBLs were also well-represented (Celenza et al., 2006; Endimiani et al., 2006; Shahcheraghi et al., 2009; Glupczynski et al., 2010). While BEL-1 (Poirel et al., 2005; Bogaerts et al., 2007) and CTX-M (al Naiemi et al., 2006; Picao et al., 2009b) ESBLs are not frequently observed in P. aeruginosa, they were the predominant ESBLs reported in $\mathrm{ESBL}^{+} P$. aeruginosa in a Belgium study (Glupczynski et al., 2010) and a Bolivian study (Celenza et al., 2006), respectively. Recently, a second BEL ESBL, BEL-2 with enhanced activity against expanded-spectrum cephalosporins was recovered in Belgium (Poirel et al., 2010a). Similarly, a high prevalence of an SHV ESBL was reported in one study (Shahcheraghi et al., 2009) although this $\beta$-lactamase is seldom reported in P. aeruginosa (Mansour et al., 2009; Hocquet et al., 2010). TEM-(Dubois et al., 2005; Shahcheraghi et al., 2009) and GES-(Labuschagne et al., 2008; Picao et al., 2009a; Viedma et al., 2009; Kotsakis et al., 2010) type ESBLs have also been described in $P$. aeruginosa.

Class D OXA enzymes (so named because of their preference for oxacillin and cloxacillin over benzylpenicillin, though not all class D enzymes show this property), are mostly narrow-spectrum $\beta$-lactamases that confer resistance to amino- and carboxypenicillins and narrow-spectrum cephalosporins (Poirel et al., 2010b) although several OXA-type enzymes are ESBLs (reviewed in Poirel et al., 2010b). Occurring predominantly in P. aeruginosa these confer resistance to cefotaxime (Danel et al., 1999; Aubert et al., 2001; Fournier et al., 2010) or ceftazidime (Toleman et al., 2003; Juan et al., 2009; Fournier et al., 2010; Hocquet et al., 2010), with some OXA $\beta$-lactamases also linked to resistance and/or reduced susceptibility to cefepime (Aubert et al., 2001; Toleman et al., 2003; Juan et al., 2009; Fournier et al., 2010; Liu et al., 2010) and/or aztreonam (Toleman et al., 2003; Juan et al., 2009; Fournier et al., 2010).

Carbapenemases. Carbapenems (e.g., meropenem, imipenem) are an important class of anti-pseudomonal $\beta$-lactam owing to their stability to most $\beta$-lactamases (see El Gamal and Oh, 2010 for a recent review of carbapenems) and are of particular use in treating infections associated with ESBL- and AmpC-producers. $\beta$-lactamases capable of hydrolyzing carbapenems are known 
(reviewed in Queenan and Bush, 2007; Walsh, 2010) and include class A and class D carbapenemases (the latter also referred to as carbapenem-hydrolyzing class D $\beta$-lactamases, CHDLs; Poirel et al., 2010b) and class B metallo- $\beta$-lactamases (MBLs; reviewed in Walsh et al., 2005), though there are no hitherto reports of CHDLs in $P$. aeruginosa.

Class A $\beta$-lactamases with activity against carbapenems are uncommon and can be divided into five groups (GES, IMI, KPC, NMC-A, and SME; reviewed in Walther-Rasmussen and Hoiby, 2007) of which only GES and KPC enzymes have been described to date in P. aeruginosa (Zhao and $\mathrm{Hu}, 2010$ ). KPC enzymes show activity against most $\beta$-lactams including oxyiminocephalosporins, monobactams, and carbapenems and while they occur as yet rarely in $P$. aeruginosa (only KPC-2 and KPC-5 have been reported in this organism) the number of reports of KPC-producing $P$. aeruginosa is increasing (Villegas et al., 2007; Akpaka et al., 2009; Wolter et al., 2009a; Poirel et al., 2010c). Interestingly, KPC-2 is more active against carbapenems than is KPC-5 while the latter shows better activity against ceftazidime (Wolter et al., 2009b). Of note, too, the presence of KPC enzymes in carbapenem-resistant isolates is often coupled with loss of the OprD outer membrane porin (Villegas et al., 2007; Wolter et al., 2009a) that is the primary route of entry of these agents into P. aeruginosa (Trias and Nikaido, 1990). While all GES enzymes are ESBLs three of these also show reasonable activity against carbapenems (GES-2, -4, and -5), with GES-2 and -5 having been reported in $P$. aeruginosa (Walther-Rasmussen and Hoiby, 2007; Viedma et al., 2009; Wang et al., 2010).

Class B MBLs are by far the major determinants of $\beta$-lactamasemediated resistance to carbapenems and the major cause of highlevel resistance to these agents. Acquired MBLs include the VIM and IMP enzymes, of which there are numerous variants of the original VIM-1 and IMP-1 MBLs, as well as the SPM-1, GIM-1, NDM1, AIM-1, and SIM-1 enzymes (Gupta, 2008; Walsh, 2010). The VIM and IMP enzymes are by far the most common MBLs found in carbapenem-resistant bacteria (Walsh et al., 2005), including carbapenem-resistant P. aeruginosa (Gupta, 2008). The predominance of VIM vs. IMP in $P$. aeruginosa appears to be geographical, with IMP-type MBLs predominating in Asia where it was first discovered and VIM-type enzymes predominating in Europe though both enzymes are now disseminated globally, with VIM-2 in particular well established on five continents (Gupta, 2008; Walsh, 2010; Zhao and $\mathrm{Hu}, 2010)$. There are single reports, only, of the GIM-1 (found in five isolates from Germany; Castanheira et al., 2004) and the AIM-1 (Gupta, 2008) MBLs in P. aeruginosa. SPM-1 is the predominant MBL in Brazil (Sader et al., 2005; Picao et al., 2009a) and while previously found only in Brazilian clinical isolates it has now been reported in Europe (Salabi et al., 2010).

\section{EFFLUX}

Five families of efflux systems that export and provide resistance to antimicrobials in bacteria have been described (Li and Nikaido, 2009) although members of the Resistance Nodulation Division (RND) family appear to be the most significant contributors to antimicrobial resistance in P. aeruginosa (Poole, 2004a, 2007). There are 12 RND-type efflux systems present in P. aeruginosa of which three, MexAB-OprM, MexCD-OprJ, and MexXY-OprM have been shown to accommodate and provide resistance to $\beta$-lactams
(Poole, 2004b). MexAB-OprM accommodates the broadest range of $\beta$-lactams (amongst these pumps) and is most frequently linked to $\beta$-lactam resistance in clinical isolates (Drissi et al., 2008; Tomas et al., 2010). The MexXY-OprM efflux system has also been linked to $\beta$-lactam resistance in clinical isolates of $P$. aeruginosa (as one of several contributors; Maniati et al., 2007; Vettoretti et al., 2009). While MexAB-OprM, MexCD-OprJ, and MexXY-OprM have all been shown to accommodate carbapenems (except imipenem; Okamoto et al., 2002) MexAB-OprM is by far the better exporter of these agents and the pump has been shown to contribute to reduced susceptibility to meropenem in clinical isolates (Pai et al., 2001; Pournaras et al., 2005). Still, efflux appears to be a minor contributor to carbapenem resistance in this organism, typically operating in conjunction with other mechanisms (Quale et al., 2006; Dotsch et al., 2009; Hammami et al., 2009; Wang et al., 2010). MexAB-OprM has also been implicated in resistance to the penicillin ticarcillin (Boutoille et al., 2004; Cavallo et al., 2007; Hocquet et al., 2007) and its expression linked statistically to aztreonam resistance (Quale et al., 2006). MexXY production, too, has been noted in ticarcillin-resistant $P$. aeruginosa (Hocquet et al., 2007) although a contribution to resistance was not proven and this efflux system is more commonly associated with resistance to the fourth generation cephalosporin cefepime in clinical isolates (Hocquet et al., 2006; Pena et al., 2009). Indeed, cefepime commonly selects for MexXY-derepressed mutants in vitro (Queenan et al., 2010). MexXY-OprM was also responsible for reduced susceptibility to ceftobiprole in a clinical study of this the novel broad-spectrum cephalosporin (Baum et al., 2009) and mutants expressing mexXY are readily selected by this $\beta$-lactam in vitro (Queenan et al., 2010). Although MexCD-OprJ accommodates cefepime (Masuda et al., 2000 ) it has rarely been linked to resistance to this agent in clinical isolates (Jeannot et al., 2008).

\section{PERMEABILITY}

By far the most common mechanism of resistance to the carbapenems (including imipenem) in P. aeruginosa is loss or alteration of the outer membrane porin protein OprD (RodriguezMartinez et al., 2009b; Wang et al., 2010), the major portal for entry for carbapenems (Trias and Nikaido, 1990). While not providing the high-level resistance seen in MBL-producers, loss of OprD function is the major determinant of non-MBL-mediated resistance to these agents (Gutierrez et al., 2007; RodriguezMartinez et al., 2009b; Tomas et al., 2010; Wang et al., 2010), often seen operating in conjunction with other mechanisms [e.g., derepressed ampC (Gutierrez et al., 2007; RodriguezMartinez et al., 2009b; Tomas et al., 2010; Wang et al., 2010) or MexAB-OprM (Gutierrez et al., 2007; Tomas et al., 2010; Wang et al., 2010) ]. Indeed, carbapenem resistance resulting from loss of OprD requires the presence of AmpC (inducible or stably derepressed; Livermore, 1992).

\section{RESISTANCE TO FLUOROQUINOLONES}

Fluoroquinolones (FQs), particularly ciprofloxacin, are commonly used in the treatment of $P$. aeruginosa infections. Resistance to these agents, particularly high-level resistance, is predominantly mediated by mutations in the DNA gyrase and topoismerase IV enzymes that are the targets of the FQs, though efflux is a significant 
contributing actor (Jacoby, 2005; Drlica et al., 2009) often in combination with target site mutations (Higgins et al., 2003; Henrichfreise et al., 2007; Rejiba et al., 2008; Tam et al., 2010).

\section{TARGET SITE MUTATIONS}

The FQ class of antimicrobial acts on bacterial topoisomerases [topoisomerase II (a.k.a. gyrase) and topoisoemrase IV] that are responsible for the introduction and/or removal of supercoils in, as well as catenation/decatenation of DNA and, thus, play an essential role in DNA replication, transcription, recombination, and repair (Drlica and Zhao, 1997). In Gram-negative bacteria, gyrase is the preferred target of FQs, and resistance mutations thus tend to occur in this enzyme first with additional mutations in topoisomerase IV seen in some highly resistant isolates (Jacoby, 2005). DNA gyrase (GyrA and GyrB) and topoisomerase (ParC and ParE) are each comprised of two subunits, with FQ resistance mutations typically occurring in the so-called "quinolone resistance determining region" (QRDR) of GyrA and/or ParC (Jacoby, 2005; Drlica et al., 2009). Such mutations are common in FQ-resistant P. aeruginosa (Higgins et al., 2003; Lee et al., 2005; Muramatsu et al., 2005; Henrichfreise et al., 2007; Rejiba et al., 2008) with highly resistant isolates carrying multiple mutations in gyrA and/ or parC (Nakano et al., 1997; Higgins et al., 2003; Lee et al., 2005; Muramatsu et al., 2005), with mutations in gyrB (Lee et al., 2005; Muramatsu et al., 2005; Schwartz et al., 2006) and parE (Lee et al., 2005; Rejiba et al., 2008) less common.

\section{EFFLUX}

Four members of the RND family of multidrug efflux systems, MexAB-OprM, MexCD-OprJ, MexEF-oprN, and MexXY-OprM are known to accommodate FQs (Poole, 2000) and these efflux systems have been implicated in FQ resistance in clinical isolates (Poole, 2000; Wolter et al., 2004; Zhanel et al., 2004; Reinhardt et al., 2007). Expression of mexAB-oprM is controlled directly or indirectly by three repressors, MexR (Srikumar et al., 2000), NalD (Morita et al., 2006) and NalC (Cao et al., 2004), and mutations in mexR (Henrichfreise et al., 2007), nalC (Henrichfreise et al., 2007) and nalD (Tomas et al., 2010) have been reported in FQ-resistant clinical isolates. mexCD-oprJ expression is controlled by a single known regulator, the NfxB repressor (Poole et al., 1996), and lab (Poole et al., 1996) and clinical (Jalal et al., 2000; Higgins et al., 2003; Henrichfreise et al., 2007) isolates expressing this efflux system and resistant to FQs invariably contain mutations in $n f x B$ (Jalal et al., 2000; Higgins et al., 2003; Henrichfreise et al., 2007). Still, mexCD-oprJ-expressing mutants appear to be rare in a clinical setting (Jeannot et al., 2008; Kiser et al., 2010). Unlike the other FQ-exporting RND-type efflux systems, expression of mexEF-oprN is regulated by a transcriptional activator, MexT (Köhler et al., 1999; Ochs et al., 1999). Unusually, many wild type stains carry inactivating mutations in mexT (Maseda et al., 2000), with mexEF-oprN expression and resistance resulting from reversion of these mutations (Maseda et al., 2000). These so-called $n f x C$ mutants (Köhler et al., 1997), which have been described in the clinic (Fukuda et al., 1995; Jalal et al., 2000), also show resistance to carbapenems such as imipenem, though not because MexEF-orpN accommodates these agents but because of a coordinate, MexT-dependent reduction of OprD in such mutants (Köhler et al., 1999; Ochs et al., 1999).
Hyperexpression of this efflux system (and reduction in OprD production) is also seen in lab isolates disrupted in the mexS gene encoding a putative oxidoreductase (a.k.a qrh; Köhler et al., 1999) of unknown function (Sobel et al., 2005). Expression of mexXY is controlled by a single known regulator, the MexZ repressor (Matsuo et al., 2004), and mexZ mutations have been reported in lab-selected FQ-resistant isolates hyperexpressing mexXY (Hocquet et al., 2008). mexXY-hyperexpressing FQ-resistant isolates lacking mutations in mexZ have also been described although the mutation(s) responsible were not identified (Hocquet et al., 2008). Despite its ability to accommodate FQs, however, MexXY-OprM has seldom been linked to FQ resistance in clinical isolates (Wolter et al., 2004).

\section{RESISTANCE TO AMINOGLYCOSIDES}

A number of aminoglycosides are commonly used in the treatment of $P$. aeruginosa infections (e.g., tobramycin, gentamicin, amikacin; Gilbert et al., 2003; Bartlett, 2004), particularly pulmonary infections in patients with cystic fibrosis (CF) where amikacin and, in particular, tobramycin are routinely employed (Canton et al., 2005; Taccetti et al., 2008). Their use is, however, linked to resistance development, with acquired aminoglycoside-modifying enzymes (AMEs) and rRNA methylases, and endogenous efflux mechanisms typically responsible (Poole, 2005).

\section{AMINOGLYCOSIDE-MODIFYING ENZYMES}

Aminoglycoside modification leading to antibiotic inactivation typically involves their phosphorylation (by aminoglycoside phosphoryltransferases, APHs), acetylation (by aminoglycoside acetyltransferases, AACs), or adenylation (by aminoglycoside nucleotidyltransferases, ANTs; aka. aminoglycoside adenylyltransferase, AAD; see Ramirez and Tolmasky, 2010 for a recent review of these modifying enzymes). AMEs are common determinants of aminoglycoside resistance in P. aeruginosa (reviewed in detail in Poole, 2005) except in CF isolates where these mechanisms are almost unknown (Shawar et al., 1999; Henrichfreise et al., 2007; Islam et al., 2009). Genes for AMEs are typically found on integrons with other resistance genes (Poole, 2005; Ramirez and Tolmasky, 2010) and, as such, AME-haboring isolates are often multidrug-resistant.

\section{Aminoglycoside acetyltransferases}

Acetylation of aminoglycosides can occur at 1-, 3-, 6'-, and $2^{\prime}$-amino groups and involve virtually all medically useful compounds (e.g., gentamicin, tobramycin, and amikacin; Ramirez and Tolmasky, 2010). Enzymes that modify the 3 [3-N-aminoglycoside acetyltransferases, $\mathrm{AAC}(3)$ ] (Biddlecome et al., 1976) and 6' [6'- $\mathrm{N}$-aminoglycoside acetyltransferases, AAC $\left(6^{\prime}\right)$ ] (Haas et al., 1976) positions are the most common acetyltransferases (Ramirez and Tolmasky, 2010) and, with ANT(2") (see below) the most common enzymes providing for aminoglycoside resistance in this organism (Poole, 2005; Shahid and Malik, 2005; Dubois et al., 2008). The AAC(3) family, of which five subfamilies have been described in P. aeruginosa (I, II, II, IV, and VI; Kim et al., 2008; Zhao et al., 2009; Ramirez and Tolmasky, 2010), is a common determinant of gentamicin resistance in this organism, less commonly contributing to tobramycin resistance (subfamilies II, III, and VI; Poole, 2005). The AAC(6') family, of which two major subfamilies have 
been described in P. aeruginosa (I and II; and many variants of the I subfamily; Ramirez and Tolmasky, 2010), is the major AAC family contributing to aminoglycoside resistance in $P$. aeruginosa, with subfamily II predominating (Poole, 2005). AAC(6') enzymes are major determinants of resistance to tobramycin and amikacin (subfamily I) and tobramycin and gentamicin (subfamily II; Poole, 2005), although some subfamily I variants lack activity against amikacin (e.g., Ib, Ib'; Galimand et al., 1993; MacLeod et al., 2000). Owing to irregularities in $\mathrm{AAC}\left(6^{\prime}\right)$ nomenclature, several of these enzymes that have been reported in $P$. aeruginosa lack a roman numeral subclass designation (e.g., AAC (6')-29a, -29b, -30, -32, -33; Ramirez and Tolmasky, 2010) and of these AAC(6')-29a and -29b provide resistance to amikacin and tobramycin (Poirel et al., 2001) while $\mathrm{AAC}\left(6^{\prime}\right)-30$ exists as part of a bifunctional $\mathrm{AAC}\left(6^{\prime}\right)-30$ / $\mathrm{AAC}\left(6^{\prime}\right)-\mathrm{Ib}^{\prime}$ enzyme that promotes resistance to tobramycin and only reduced susceptibility to amikacin and gentamicin (Mendes et al., 2004). A novel aminoglycoside acetyltransferase that exhibits FQ-acetylating activity, AAC $\left(6^{\prime}\right)$-Ib-cr, has also been described in $P$. aeruginosa (Libisch et al., 2008).

\section{Aminoglycoside nucleotidyltransferases}

The most prevalent nucleotidyltransferase in P. aeruginosa is the ANT(2')-I enzyme which inactivates gentamicin and tobramycin but not amikacin and is, thus, found in gentamicin- and tobramycin-resistant clinical isolates (Poole, 2005). A less common nucleotidyltransferases associated with aminoglycoside resistance in $P$. aeruginosa is ANT( $\left.4^{\prime}\right)$-II which provides resistance to tobramycin and amikacin (Poole, 2005; Ramirez and Tolmasky, 2010). Two variants of this enzyme, ANT(4')-IIa (Shaw et al., 1993) and -IIb (Sabtcheva et al., 2003) have been described in amikacinresistant clinical isolates and there is a report of an ant $\left(4^{\prime}\right)-I$ gene in $P$. aeruginosa although its contribution to resistance was not established (Jin et al., 2009). While there are a number of reports of the ANT $\left(3^{\prime}\right)$ nucleotidyltransferase in P. aeruginosa (Ramirez and Tolmasky, 2010) this enzyme is active against streptomycin and none of the clinically used anti-pseudomonal aminoglycosides.

\section{Aminoglycoside phosphoryltransferases}

Aminoglycoside phosphoryltransferases found in P. aeruginosa are almost invariably $3^{\prime}$ enzymes that act on the $3-\mathrm{OH}$ of target aminoglycosides and generally provide resistance to aminoglycosides not typically used to treat $P$. aeruginosa infections (kanamycin, neomycin, and streptomycin; Poole, 2005). APH(3')-II predominates in clinical isolates resistant to kanamycin (and neomycin; Miller et al., 1994; Poole, 2005) and, indeed, a chromosomal aphA-encoded APH(3')-II type enzyme, $\mathrm{APH}\left(3^{\prime}\right)$-IIb (Hachler et al., 1996) is likely responsible for the general insensitivity of $P$. aeruginosa to kanamycin. APH enzymes that provide resistance to other aminoglycosides have also been described in P. aeruginosa and include APH( $\left.3^{\prime}\right)$-VI (amikacin; Kettner et al., 1995; Kim et al., 2008; Jin et al., 2009), APH(3')-IIb-like (amikacin, weakly; Riccio et al., 2001), and APH(2") (gentamicin and tobramycin; Kettner et al., 1995).

\section{EFFLUX}

Aminoglycoside resistance independent of inactivating enzymes has been known for some time in P. aeruginosa (Bryan et al., 1976). Characterized by resistance to all aminoglycosides and often associated with reduced aminoglycoside accumulation (Bryan et al., 1976) such resistance, particularly common in CF isolates (reviewed in Poole, 2005), was attributed to reduced uptake owing to reduced permeability and, as such, was typically referred to as impermeability resistance. It is now known, however, that this resistance was likely due to efflux mediated by the MexXY-OprM multidrug efflux system. Indeed, this efflux system has been implicated in aminoglycoside resistance in clinical isolates, particularly CF isolates, in a number of studies (Sobel et al., 2003; Hocquet et al., 2006; Henrichfreise et al., 2007; Islam et al., 2009).

The MexXY-OprM system is encoded by the mexXY operon that is under the control of the MexZ repressor (Matsuo et al., 2004) and the oprM gene of the mexAB-oprM multidrug efflux operon. Mutations in mex $Z$ are common in pan-aminoglycosideresistant $\mathrm{CF}$ isolates of $P$. aeruginosa expressing mexXY (Poole, 2005; Hocquet et al., 2006; Henrichfreise et al., 2007; Islam et al., 2009; Feliziani et al., 2010) with mexZ, in fact, identified as the most commonly mutated gene in CF isolates (Smith et al., 2006; Feliziani et al., 2010). A number of studies highlight, however, the absence of mutations in mex $Z$ or the mexXY promoter region in mexXY-expressing aminoglycoside-resistant CF isolates (Sobel et al., 2003; Hocquet et al., 2006; Islam et al., 2009), indicating that additional genes/mutations are linked to expression of this efflux locus in $P$. aeruginosa. A recent report of an in vitro-selected mexXY-expressing aminoglycoside-resistant mutant lacking a mex $Z$ mutation identified a novel gene, $p a r R$, as the site of mutation (Muller et al., 2010). parR forms part of a two-gene operon, parRS, encoding a two-component regulatory systems that impacts expression of several antimicrobial resistance determinants in $P$. aeruginosa (e.g., oprD), including mexXY. Significantly, mutations in parR are present in some clinical isolates that express mex $X Y$ but lack mutations in mexZ (Muller et al., 2010).

\section{S rRNA METHYLASES}

A more recently discovered aminoglycoside resistance mechanism involves methylation of the $16 \mathrm{~S}$ rRNA of the A site of the 30 S ribosomal subunit, which interferes with aminoglycoside binding and so promotes high-level resistance to clinically relevant aminoglycosides like gentamicin, tobramycin, and amikacin (reviewed in Doi and Arakawa, 2007). A number of different pan-aminoglycoside resistance-promoting 16S rRNA methylases have been described in P. aeruginosa, including RmtA (Yamane et al., 2004; Jin et al., 2009), RmtB (Zhou et al., 2010), RmtD (Doi et al., 2007; Lincopan et al., 2010), and ArmA (Gurung et al., 2010; Zhou et al., 2010). RmtD is frequently co-produced with the SPM-1 MLB that predominates in Brazil (Doi et al., 2007; Lincopan et al., 2010) and co-carriage of ArmA and the IMP-1 MBL has also been reported in P. aeruginosa isolates from Korea (Gurung et al., 2010).

\section{RESISTANCE TO POLYCATIONIC ANTIMICROBIALS}

Owing to the increased prevalence of multidrug-resistant $P$. aeruginosa, "older" antimicrobials like the polymyxins (polymyxin B and colistin) are back in favor, with earlier issues surrounding nephrotoxicity largely dealt with (Zavascki et al., 2007; Molina et al., 2009). While these agents, and colistin in particular, are quite efficacious in the treatment of multidrug-resistant $P$. aeruginosa infections (Montero et al., 2009; Falagas et al., 2010) there are 
reports of resistance to both polymyxin B (Landman et al., 2005; Abraham and Kwon, 2009; Barrow and Kwon, 2009) and colistin (Johansen et al., 2008; Matthaiou et al., 2008; Samonis et al., 2010) in clinical isolates. While in many cases the mechanism(s) of clinical polymyxin resistance are unknown, substitution of LPS lipid A with aminoarabinose has been shown to contribute to polymyxin resistance in $P$. aeruginosa in vitro (Moskowitz et al., 2004) and in CF isolates (Ernst et al., 1999). This modification is carried out by the products of the arnBCADTEF-ugd locus (a.k.a. pmrHFIJKLM-ugd and PA3552-59) that is regulated both by PhoPQ (Macfarlane et al., 2000) and a second two-component regulatory system, PmrAB (McPhee et al., 2003; Moskowitz et al., 2004), with mutations in $p h o Q$ and $p m r B$ shown to promote ArnBCADTEF-dependent polymyxin B resistance in clinical isolates (Abraham and Kwon, 2009; Barrow and Kwon, 2009). A third two-component system, ParRS, also controls arnBCADTEF-ugd expression (Fernandez et al., 2010), with a mutation in parR linked to ArnBCADTEF-mediated polymyxin resistance in a lab isolate (Muller et al., 2010). parR (and parS) mutations have been noted in clinical isolates, although there was no indication that the arn locus was upregulated, and the polymyxin resistance of these isolates was minimal (Muller et al., 2010).

\section{BIOFILM RESISTANCE}

Biofilms, surface-attached three-dimensional structures in which bacteria are imbedded in a matrix comprised of polysaccharide, protein, and DNA, are increasingly recognized as the preferred mode of bacterial growth in nature and infectious disease (Lopez et al., 2010). This is true of $P$. aeruginosa (Harmsen et al., 2010), particularly in the case of pulmonary infections in patients with CF (Wagner and Iglewski, 2008; Davies and Bilton, 2009). An important consequence of $P$. aeruginosa biofilm growth and one that is particularly relevant in a clinical context is marked resistance to antimicrobial agents (Davies and Bilton, 2009; Hoiby et al., 2010). Antimicrobial resistance of $P$. aeruginosa biofilms appears to be complex, multifactorial, and in many instances not well understood (Drenkard, 2003; Hoiby et al., 2010). Some studies indicate that $P$. aeruginosa within biofilms are metabolically less active and grow more slowly than cells at the biofilm periphery (owing to limited access to nutrients and oxygen; Werner et al., 2004), which may contribute to increasing biofilm tolerance to antimicrobials since antimicrobials often target metabolically active cells (Pamp et al., 2008). Certainly, the suggestion that biofilm-grown $P$. aeruginosa from CF patients are anaerobic (Hassett et al., 2009) is likely to be significant in the context of antimicrobial resistance since many agents are inactive or less active under anaerobiosis (Schobert and Tielen, 2010). Oxygen limitation has, in fact, been shown to contribute significantly to the antimicrobial resistance of in vitro-grown $P$. aeruginosa biofilms (Borriello et al., 2004).

One explanation for biofilms being generally refractory to antimicrobial chemotherapy is the presence, in biofilms, of a highly resistant sub-population of cells called persisters (Lewis, 2008). Intriguingly, "late" isolates of $P$. aeruginosa in CF (those recovered later in infection) produce increased levels of drug-tolerant persister cells, which may be the primary "mechanism" for surviving chemotherapy and, so, may explain the general recalcitrance of
P. aeruginosa infections in CF (Mulcahy et al., 2010). The idea of a sub-population of biofilm cells displaying different patterns of antimicrobial susceptibility is supported by a recent study showing that only the mobile cells responsible for forming the "cap" component of the typical $P$. aeruginosa biofilm mushroom structures exhibited tolerance to colistin, as a result of colistin triggering PmrAB-dependent expression of the arn LPS modification locus (Haagensen et al., 2007; Pamp et al., 2008). While the details of persister formation and the mechanism(s) responsible for persister resistance remain unknown, a preliminary screen of a transposon insertion mutant library for mutants showed altered persister formation identified several genes whose disruption either increased or decreased persister formation (De Groote et al., 2009).

Aminoglycosides have been shown to induce biofilm formation by $P$. aeruginosa, in a process that requires a gene, arr (aminoglycoside response regulator; Hoffman et al., 2005). arr encodes a phosphodiesterase that impacts the levels of bis- $\left(3^{\prime}, 5^{\prime}\right)$-cyclic-diguanidine monophosphate (c-di-GMP; Hoffman et al., 2005), a second messenger known to influence biofilm formation (Harmsen et al., 2010) and lack of arr compromises biofilm resistance to aminoglycosides (Hoffman et al., 2005). Given that c-di-GMP production is generally correlated with biofilm formation (Harmsen et al., 2010) it is unclear how Arr-promoted turnover of this second messenger would promote biofilm formation. A second gene linked to biofilm-specific resistance to aminoglycosides in some strains only, $n d v B$, is involved in the synthesis of periplasmic (and intracellular) glucans that bind aminoglycosides (tobramycin), suggestive of a mechanism of resistance whereby aminoglycosides are sequestered and prevented from reaching their targets in the cytosol (Mah et al., 2003). These glucans, which have recently been purified and identified as highly glycerol-phosphorylated $\beta-(1 \rightarrow 3)$ glucans, actually form part of the biofilm matrix where they do, indeed, bind aminoglycosides (Sadovskaya et al., 2010). A tripartite ABC-family efflux system that is preferentially expressed in biofilm vs. planktonic cells, PA1875-PA1876-PA1877, has also been linked to biofilm-specific aminoglycoside résistance (Zhang and Mah, 2008). Efflux (mediated by MexCD-OprJ) has also been linked to biofilm-specific resistance to azithromycin in $P$. aeruginosa (Gillis et al., 2005; Mulet et al., 2009).

\section{HYPERMUTATION AND RESISTANCE}

Hypermutable (or mutator) $P$. aeruginosa exhibiting increased mutation rates are common in chronic infections such as those that occur in the lungs of CF patients (see Oliver, 2010; Oliver and Mena, 2010; for reviews of hypermutation in CF isolates). The hypermutation phenotype of mutator stains results from defects in DNA repair, predominantly in the mismatch repair (MMR) system (Oliver, 2010), with mutations in mutS (Oliver et al., 2002; Macia et al., 2005; Feliziani et al., 2010), mutL (Oliver et al., 2002; Feliziani et al., 2010), and $u v r D$ (a.k.a mutU; Oliver et al., 2002) typically responsible. Significantly from an antimicrobial resistance standpoint, mutator strains show higher rates of antimicrobial resistance development than non-mutator strains (Oliver et al., 2000; Ferroni et al., 2009), with the mutator phenotype of CF isolates often correlating with antimicrobial, including multidrug, resistance (Macia et al., 2005; Waine et al., 2008; Ferroni et al., 2009; Feliziani et al., 2010; Tam et al., 2010; reviewed in Oliver, 2010). 
A second DNA repair system less commonly linked to the mutator phenotype in P. aeruginosa is the DNA oxidative repair (GO) system charged with repairing and preventing incorporation into DNA of an oxidatively damaged form of guanosine (8-oxo- $2^{\prime}$ deoxyguanosine, 8-oxodG; Oliver and Mena, 2010). In vitro studies have shown that knockouts in the GO genes mutT and mut $Y$ yield increased mutation rates concomitant with increased oxidative damage of DNA (Mandsberg et al., 2009), with mutT (Mandsberg et al., 2009; Morero and Argarana, 2009) and mutY (Mandsberg et al., 2009) strains also showing higher rates of antimicrobial resistance. Given that the characteristically chronically inflamed CF lung is an environment rich in reactive oxygen species (ROS) that can damage DNA, the potential for ROS-promoted hypermutability owing to defects in the GO system is certainly real. Although uncommon, mutator strains with lesions in mutT and mut $Y$ have been recovered from CF patients (Mandsberg et al., 2009).

\section{CONCLUDING REMARKS}

Rates of infection and resistance are increasing in $P$. aeruginosa (Talbot et al., 2006; Kerr and Snelling, 2009), and with reports of colistin-only sensitive $P$. aeruginosa and the presence of colistinresistance in this organism the untreatable $P$. aeruginosa infection may be imminent. Compounding the increasing lack of effective anti-pseudomonal agents is the paucity of new drugs being developed that are active against $P$. aeruginosa and, indeed, the absence of any late-stage agents effective against pan-resistant $P$. aeruginosa (Talbot et al., 2006; Boucher et al., 2009; Page and Heim, 2009). The few novel agents with anti-pseudomonad activ-

\section{REFERENCES}

Abraham, N., and Kwon, D. H. (2009). A single amino acid substitution in $\mathrm{PmrB}$ is associated with polymyxin B resistance in clinical isolate of Pseudomonas aeruginosa. FEMS Microbiol. Lett. 298, 249-254.

Akpaka, P. E., Swanston, W. H., Ihemere, H. N., Correa, A., Torres, J. A., Tafur, J. D., Montealegre, M. C., Quinn, J. P., and Villegas, M. V. (2009). Emergence of KPC-producing Pseudomonasaeruginosa in Trinidad and Tobago. J. Clin. Microbiol. 47, 2670-2671.

al Naiemi, N., Duim, B., and Bart, A. (2006). A CTX-M extended-spectrum $\beta$-lactamase in Pseudomonas aeruginosa and Stenotrophomonas maltophilia. J. Med. Microbiol. 55, 1607-1608.

Arora, S., and Bal, M. (2005). AmpC $\beta$-lactamase producing bacterial isolates from Kolkata hospital. Indian J. Med. Res. 122, 224-233.

Aubert, D., Poirel, L., Chevalier, J., Leotard, S., Pages, J. M., and Nordmann, P. (2001). Oxacillinase-mediated resistance to cefepime and susceptibility to ceftazidime in Pseudomonas aeruginosa. Antimicrob. Agents Chemother. 45, 1615-1620.

Barrow, K., and Kwon, D. H. (2009). Alterations in two-component

ity (e.g., the siderophore-monobactam hybrid, BAL30072, the anti-pseudomonal cephalosporin CXA-101, and the MBL inhibitor ME1071) are, unfortunately, negatively impacted by known resistance mechanisms (Page and Heim, 2009). While the lack of classical antimicrobial options has prompted research into novel anti-pseudomonal strategies/agents, including a humaneered antiP. aeruginosa Fab antibody fragment, KB001, cationic antimicrobial peptides, efflux pump inhibitors, modulators of virulence (Page and Heim, 2009; Veesenmeyer et al., 2009), and phage therapy (Wright et al., 2009), only KB001 is in later stage clinical trials (Page and Heim, 2009). Clearly, more therapeutic options are needed. Given the resistance armamentarium available to $P$. aeruginosa and the observation that drug use begets resistance, more also needs to be done in the areas of antimicrobial stewardship, resistance surveillance, and infection control (Kerr and Snelling, 2009). With limited (and shrinking) options, and an environment where anti-infectives, generally, are not being developed and fewer and fewer resources are being devoted to this therapeutic area by the major pharmaceutical companies (Boucher et al., 2009) prudent management of available agents and more robust resistance monitoring and infection control practices are essential. While these will likely not prevent the rise of untreatable pan-resistant $P$. aeruginosa, hopefully their numbers and impact can be limited.

\section{ACKNOWLEDGMENTS}

Work on antimicrobial resistance in the Poole lab is supported by operating grants from the Canadian Cystic Fibrosis Foundation and the Canadian Institutes of Health Research.

to antibiotic tolerance of Pseudomonas aeruginosa in biofilms. Antimicrob. Agents Chemother. 48, 2659-2664.

Boucher, H. W., Talbot, G. H., Bradley, J. S., Edwards, J. E., Gilbert, D., Rice, L. B., Scheld, M., Spellberg, B., and Bartlett, J. (2009). Bad bugs, no drugs: no ESKAPE! An update from the Infectious Diseases Society of America. Clin. Infect. Dis. 48, 1-12.

Boutoille, D., Corvec, S., Caroff, N., Giraudeau, C., Espaze, E., Caillon, J., Plesiat, P., and Reynaud, A. (2004). Detection of an IS21 insertion sequence in the mex $R$ gene of Pseudomonas aeruginosa increasing $\beta$-lactam resistance. FEMS Microbiol. Lett. 230, 143-146.

Bratu, S., Landman, D., Gupta, J., and Quale, J. (2007). Role of AmpD, OprF and penicillin-binding proteins in $\beta$-lactam resistance in clinical isolates of Pseudomonas aeruginosa. J. Med. Microbiol. 56, 809-814.

Bryan, L. E., Haraphongse, R., and Van den Elzen, H. M. (1976). Gentamicin resistance in clinical-isolates of Pseudomonas aeruginosa associated with diminished gentamicin accumulation and no detectable enzymatic modification. J. Antibiot. 29, 743-753.

Bush, K. (2008). Extended-spectrum $\beta$-lactamases in North America,
1987-2006. Clin. Microbiol. Infect. 14(Suppl. 1), 134-143.

Cambray, G., Guerout, A. M., and Mazel, D. (2010). Integrons. Annu. Rev. Genet. 44, 141-166.

Canton, R., Cobos, N., de Gracia, J., Baquero, F., Honorato, J., Gartner S., Alvarez, A., Salcedo, A., Oliver, A., and Garcia-Quetglas, E. (2005). Antimicrobial therapy for pulmonary pathogenic colonisation and infection by Pseudomonas aeruginosa in cystic fibrosis patients. Clin. Microbiol. Infect. 11, 690-703.

Cao, L., Srikumar, R., and Poole, K. (2004). MexAB-OprMhyperexpression in NalC type multidrug resistant Pseudomonas aeruginosa: identification and characterization of the nalC gene encoding a repressor of PA3720-PA3719. Mol. Microbiol. 53, 1423-1436.

Castanheira, M., Bell, J. M., Turnidge, J. D., Mathai, D., and Jones, R. N. (2009).Carbapenem resistance among Pseudomonas aeruginosa strains from India: evidence for nationwide endemicity of multiple metallo- $\beta$ lactamase clones (VIM-2, -5, -6, and -11 and the newly characterized VIM18). Antimicrob. Agents Chemother. 53, 1225-1227.

Castanheira, M., Toleman, M. A., Jones, R. N., Schmidt, F. J., and Walsh, T. R. 
(2004). Molecular characterization of a $\beta$-lactamase gene, blaGIM- 1 , encoding a new subclass of metallo$\beta$-lactamase. Antimicrob. Agents Chemother. 48, 4654-4661.

Cavallo, J. D., Hocquet, D., Plesiat, P., Fabre, R., and Roussel-Delvallez, M. (2007). Susceptibility of Pseudomonas aeruginosa to antimicrobials: a 2004 French multicentre hospital study. J. Antimicrob. Chemother. 59, 1021-1024.

Celenza, G., Pellegrini, C., Caccamo, M., Segatore, B., Amicosante, G., and Perilli, M. (2006). Spread of bla(CTXM-type) and bla(PER-2) $\beta$-lactamase genes in clinical isolates from Bolivian hospitals. J. Antimicrob. Chemother. 57, 975-978.

Danel, F., Hall, L. M., Duke, B., Gur, D., and Livermore, D. M. (1999). OXA-17, a further extended-spectrum variant of OXA-10 $\beta$-lactamase, isolated from Pseudomonas aeruginosa. Antimicrob. Agents Chemother. 43, 1362-1366.

Davies, J. C., and Bilton, D. (2009). Bugs, biofilms, and resistance in cystic fibrosis. Respir. Care 54, 628-640.

De Champs, C., Poirel, L., Bonnet, R., Sirot, D., Chanal, C., Sirot, J., and Nordmann, P. (2002). Prospective survey of $\beta$-lactamases produced by ceftazidime- resistant Pseudomonas aeruginosa isolated in a French hospital in 2000. Antimicrob. Agents Chemother. 46, 3031-3034.

De Groote, V.N., Verstraeten, N., Fauvart, M., Kint, C. I., Verbeeck, A. M., Beullens, S., Cornelis, P., and Michiels, J. (2009). Novel persistence genes in Pseudomonas aeruginosa identified by high-throughput screening. FEMS Microbiol. Lett. 297, 73-79.

Doi, Y., and Arakawa, Y. (2007). 16S ribosomal RNA methylation: emerging resistance mechanism against aminoglycosides. Clin. Infect. Dis. 45, 88-94.

Doi, Y., Ghilardi, A. C., Adams, J., de Oliveira, G. D., and Paterson, D. L. (2007). High prevalence of metallo$\beta$-lactamase and 16S rRNA methylase coproduction among imipenemresistant Pseudomonas aeruginosa isolates in Brazil. Antimicrob. Agents Chemother. 51, 3388-3390.

Dotsch, A., Becker, T., Pommerenke, C., Magnowska, Z., Jansch, L., and Haussler, S. (2009). Genomewide identification of genetic determinants of antimicrobial drug resistance in Pseudomonas aeruginosa. Antimicrob. Agents Chemother. 53, 2522-2531.

Drenkard,E. (2003). Antimicrobial resistance of Pseudomonas aeruginosa biofilms. Microbes Infect. 5, 1213-1219.

Drissi, M., Ahmed, Z. B., Dehecq, B., Bakour, R., Plesiat, P., and Hocquet, D. (2008). Antibiotic susceptibility and mechanisms of $\beta$-lactam resistance among clinical strains of Pseudomonas aeruginosa: first report in Algeria. Med. Mal. Infect. 38, 187-191.

Drlica, K., Hiasa, H., Kerns, R., Malik, M., Mustaev, A., and Zhao, X. (2009). Quinolones: action and resistance updated. Curr. Top. Med. Chem. 9, 981-998.

Drlica, K., and Zhao, X. (1997). DNA gyrase, topoisomerase IV, and the 4-quinolones. Microbiol. Mol. Biol. Rev. 61, 377-392.

Dubois, V., Arpin, C., Dupart, V., Scavelli, A., Coulange, L., Andre, C., Fischer, I., Grobost, F., Brochet, J. P., Lagrange, I., Dutilh, B., Jullin, J., Noury, P., Larribet, G., and Quentin, C. (2008). $\beta$-lactam and aminoglycoside resistance rates and mechanisms among Pseudomonas aeruginosa in French general practice (community and private healthcare centres). J. Antimicrob. Chemother. 62, 316-323.

Dubois, V., Arpin, C., Noury, P., Andre, C., Coulange, L., and Quentin, C. (2005). Prolonged outbreak of infection due to TEM-21-producing strains of Pseudomonas aeruginosa and enterobacteria in a nursing home. J Clin. Microbiol. 43, 4129-4138.

El Gamal, M. I., and Oh, C. H. (2010). Current Status of carbapenem antibiotics. Curr. Top. Med. Chem. 10, 1882-1897.

Endimiani, A., Luzzaro, F., Pini, B., Amicosante, G., Rossolini, G. M., and Toniolo, A. Q. (2006). Pseudomonas aeruginosa bloodstream infections: risk factors and treatment outcome related to expression of the PER-1 extended-spectrum $\beta$-lactamase. BMC Infect. Dis. 6, 52. doi: 10.1186/1471-2334-6-52

Ernst, R. K., Yi, E. C., Guo, L., Lim, K. B., Burns, J. L., Hackett, M., and Miller, S. I. (1999). Specific lipopolysaccharide found in cystic fibrosis airway Pseudomonas aeruginosa. Science 286, 1561-1565.

Falagas, M. E., Rafailidis, P. I., Ioannidou, E., Alexiou, V. G., Matthaiou, D. K., Karageorgopoulos, D. E., Kapaskelis, A., Nikita, D., and Michalopoulos, A. (2010). Colistin therapy for microbiologically documented multidrugresistant Gram-negative bacterial infections: a retrospective cohort study of 258 patients. Int. J. Antimicrob. Agents 35, 194-199.

Feliziani, S., Lujan, A. M., Moyano, A. J., Sola, C., Bocco, J. L., Montanaro, P., Canigia, L. F., Argarana, C. E., and Smania, A. M. (2010). Mucoidy, quorum sensing, mismatch repair and antibiotic resistance in Pseudomonas aeruginosa from cystic fibrosis chronic airways infections. PLoS
ONE 5, e12669. doi: 10.1371/journal. pone. 0012669

Fernandez, L., Gooderham, W. J., Bains, M., McPhee, J. B., Wiegand, I., and Hancock, R. E. (2010). Adaptive resistance to the "last hope" antibiotics polymyxin B and colistin in Pseudomonas aeruginosa is mediated by the novel two-component regulatory system ParR-ParS. Antimicrob. Agents Chemother. 54, 3372-3382.

Ferrara, A. M. (2006). Potentially multidrug-resistant non-fermentative Gram-negative pathogens causing nosocomial pneumonia. Int. J. Antimicrob. Agents 27, 183-195.

Ferroni, A., Guillemot, D., Moumile, K., Bernede, C., Le Bourgeois, M. Waernessyckle, S., Descamps, P., Sermet-Gaudelus, I., Lenoir, G., Berche, P., and Taddei, F. (2009). Effect of mutator P. aeruginosa on antibiotic resistance acquisition and respiratory function in cystic fibrosis. Pediatr. Pulmonol. 44, 820-825.

Fournier, D., Hocquet, D., Dehecq, B., Cholley, P., and Plesiat, P. (2010). Detection of a new extended-spectrum oxacillinase in Pseudomonas aeruginosa. J. Antimicrob. Chemother. $65,364-365$.

Fukuda, H., Hosaka, M., Iyobe, S., Gotoh, N., Nishino, T., and Hirai, K. (1995). $n f x C$-type quinolone resistance in a clinical isolate of Pseudomonas aeruginosa. Antimicrob. Agents Chemother. 39, 790-792.

Galimand, M., Lambert, T., Gerbaud, G., and Courvalin, P. (1993). Characterization of the $a a c\left(6^{\prime}\right)-I b$ gene encoding an aminoglycoside 6'- $N$-acetyltransferase in Pseudomonas aeruginosa BM2656. Antimicrob. Agents Chemother. 37, 1456-1462.

Giamarellos-Bourboulis, E. J., Papadimitriou, E., Galanakis, N., Antonopoulou, A., Tsaganos, T., Kanellakopoulou, K., and Giamarellou, H. (2006). Multidrug resistance to antimicrobials as a predominant factor influencing patient survival. Int. J. Antimicrob. Agents 27, 476-481.

Gilbert, D. N., Moellering, R. C. Jr., and Sande, M. A. (2003). The Sanford Guide to Antimicrobial Therapy 2003. Hyde Park: Antimicrobial Therapy, Inc.

Gillis, R. J., White, K. G., Choi, K. H., Wagner, V. E., Schweizer, H. P., and Iglewski, B. H. (2005). Molecular basis of azithromycin-resistant Pseudomonas aeruginosa biofilms. Antimicrob. Agents Chemother. 49, 3858-3867.

Girlich, D., Naas, T., Leelaporn, A., Poirel, L., Fennewald, M., and Nordmann, P. (2002). Nosocomial spread of the integron-located veb-1-like cassette encoding an extended-spectrum $\beta$-lactamase in Pseudomonas aeruginosa in Thailand. Clin. Infect. Dis. 34, 603-611.

Girlich, D., Naas, T., and Nordmann, P. (2004). Biochemical characterization of the naturally occurring oxacillinase OXA-50 of Pseudomonas aeruginosa. Antimicrob. Agents Chemother. 48 2043-2048.

Glupczynski, Y., Bogaerts, P., Deplano, A., Berhin, C., Huang, T. D., Van Eldere, J., and Rodriguez-Villalobos, H. (2010). Detection and characterization of class A extended-spectrum$\beta$-lactamase-producing Pseudomonas aeruginosa isolates in Belgian hospitals. J. Antimicrob. Chemother. 65, 866-871.

Gupta, V. (2008). Metallo $\beta$-lactamases in Pseudomonas aeruginosa and Acinetobacter species. Expert Opin. Investig. Drugs 17, 131-143.

Gurung, M., Moon, D. C., Tamang, M. D., Kim, J., Lee, Y. C., Seol, S. Y., Cho, D. T., and Lee, J.C. (2010). Emergence of $16 S$ rRNA methylase gene armA and cocarriage of $b a_{\mathrm{IMP}-1}$ in Pseudomonas aeruginosa isolates from South Korea. Diagn. Microbiol. Infect Dis. 68, 468-470.

Gutierrez, O., Juan, C., Cercenado, E., Navarro, F., Bouza, E., Coll, P., Perez, J. L., and Oliver, A. (2007). Molecular epidemiology and mechanisms of carbapenem resistance in Pseudomonas aeruginosa isolates from Spanish hospitals. Antimicrob. Agents Chemother. 51, 4329-4335.

Haagensen, J. A., Klausen, M., Ernst, R. K., Miller, S. I., Folkesson, A., TolkerNielsen, T., and Molin, S. (2007). Differentiation and distribution of colistin- and sodium dodecyl sulfatetolerant cells in Pseudomonas aeruginosa biofilms. J. Bacteriol. 189, 28-37.

Haas, M., Biddlecome, S., Davies, J.,Luce, C. E., and Daniels, P.J. (1976). Enzymatic modification of aminoglycoside antibiotics: a new 6'-N-acetylating enzyme from a Pseudomonas aeruginosa isolate. Antimicrob. Agents Chemother. 9 , 945-950.

Hachler, H., Santanam, P., and Kayser, F. H. (1996). Sequence and characterization of a novel chromosomal aminoglycoside phosphotransferase gene, aph (3')-IIb, in Pseudomonas aeruginosa. Antimicrob. Agents Chemother. 40, 1254-1256.

Hammami, S., Ghozzi, R., Burghoffer, B., Arlet, G., and Redjeb, S. (2009). Mechanisms of carbapenem resistance in non-metallo- $\beta$-lactamaseproducing clinical isolates of Pseudomonas aeruginosa from a Tunisian hospital. Pathol. Biol. 57 530-535. 
Harmsen, M., Yang, L., Pamp, S. J., and Tolker-Nielsen, T. (2010). An update on Pseudomonas aeruginosa biofilm formation, tolerance, and dispersal. FEMS Immunol. Med. Microbiol. 59, 253-268.

Hassett, D. J., Sutton, M. D., Schurr, M. J., Herr, A. B., Caldwell, C. C., and Matu, J. O. (2009). Pseudomonas aeruginosa hypoxic or anaerobic biofilm infections within cystic fibrosis airways. Trends Microbiol. 17, 130-138.

Helfand, M.S., and Bonomo, R.A. (2003). $\beta$-lactamases: a survey of protein diversity. Curr. Drug Targets Infect. Disord. 3, 9-23.

Henrichfreise, B., Wiegand, I., Pfister, W., and Wiedemann, B. (2007). Resistance mechanisms of multiresistant Pseudomonas aeruginosa strains from Germany and correlation with hypermutation. Antimicrob. Agents Chemother. 51, 4062-4070.

Hidron, A. I., Edwards, J. R., Patel, J., Horan, T. C., Sievert, D. M., Pollock, D. A., and Fridkin, S. K. (2008). NHSN annual update: antimicrobial-resistant pathogens associated with healthcare-associated infections: annual summary of data reported to the National Healthcare Safety Network at the Centers for Disease Control and Prevention, 2006-2007. Infect. Control Hosp. Epidemiol. 29, 996-1011.

Higgins, P. G., Fluit, A. C., Milatovic, D., Verhoef, J., and Schmitz, F. J. (2003). Mutations in GyrA, ParC, MexR and $\mathrm{NfxB}$ in clinical isolates of Pseudomonas aeruginosa. Int. J. Antimicrob. Agents 21, 409-413.

Hirsch, E. B., and Tam, V.H. (2010). Impact of multidrug-resistant Pseudomonas aeruginosa infection on patient outcomes. Expert Rev. Pharmacoecon. Outcomes Res. 10, 441-451.

Hocquet, D., Muller, A., Blanc, K., Plesiat, P., Talon, D., Monnet, D. L., and Bertrand, X. (2008). Relationship between antibiotic use and incidence of MexXY-OprM overproducers among clinical isolates of Pseudomonas aeruginosa. Antimicrob. Agents Chemother. 52, 1173-1175.

Hocquet, D., Nordmann, P., El Garch, F., Cabanne, L., and Plesiat, P. (2006). Involvement of the MexXYOprM efflux system in emergence of cefepime resistance in clinical strains of Pseudomonas aeruginosa. Antimicrob. Agents Chemother. 50, 1347-1351.

Hocquet, D., Plesiat, P., Dehecq, B., Mariotte, P., Talon, D., and Bertrand, X. (2010). Nationwide investigation of extended-spectrum $\beta$-lactamases, metallo- $\beta$-lactamases, and extendedspectrum oxacillinases produced by ceftazidime-resistant Pseudomonas aeruginosa strains in France. Antimicrob. Agents Chemother. 54, 3512-3515.

Hocquet, D., Roussel-Delvallez, M., Cavallo, J. D., and Plesiat, P. (2007). MexAB-OprM- and MexXYoverproducing mutants are very prevalent among clinical strains of Pseudomonas aeruginosa with reduced susceptibility to ticarcillin. Antimicrob. Agents Chemother. 51, 1582-1583.

Hoffman, L. R., D'Argenio, D.A., MacCoss, M. J., Zhang, Z., Jones, R. A., and Miller, S. I. (2005). Aminoglycoside antibiotics induce bacterial biofilm formation. Nature 436, 1171-1175.

Hoiby, N., Bjarnsholt, T., Givskov, M., Molin, S., and Ciofu, O. (2010). Antibiotic resistance of bacterial biofilms. Int. J. Antimicrob. Agents 35, 322-332.

Islam, S., Oh, H., Jalal, S., Karpati, F., Ciofu, O., Hoiby, N., and Wretlind, B. (2009). Chromosomal mechanisms of aminoglycoside resistance in Pseudomonas aeruginosa isolates from cystic fibrosis patients. Clin. Microbiol. Infect. 15, 60-66.

Jacoby, G.A. (2005). Mechanisms of resistance to quinolones. Clin. Infect. Dis. 41(Suppl. 2), S120-S126.

Jacoby, G. A. (2009). AmpC $\beta$-lactamases. Clin. Microbiol. Rev. 22, 161-182.

Jalal, S., Ciofu, O., Hoiby, N., Gotoh, N., and Wretlind, B. (2000). Molecular mechanisms of fluoroquinolone resistance in Pseudomonas aeruginosa isolates from cystic fibrosos. Antimicrob. Agents Chemother. 44, 710-712.

Jeannot, K., Elsen, S., Kohler, T., Attree, I., Van Delden, C., and Plesiat, P. (2008). Resistance and virulence of Pseudomonas aeruginosa clinical strains overproducing the MexCDOprJ efflux pump. Antimicrob. Agents Chemother. 52, 2455-2462.

Jiang, X., Zhang, Z., Li, M., Zhou, D., Ruan, F., and Lu, Y. (2006). Detection of extended-spectrum $\beta$-lactamases in clinical isolates of Pseudomonas aeruginosa. Antimicrob. Agents Chemother. 50, 2990-2995.

Jin, J.S., Kwon, K. T., Moon, D. C., and Lee, J. C. (2009). Emergence of $16 \mathrm{~S}$ rRNA methylase rmtA in colistin-onlysensitive Pseudomonas aeruginosa in South Korea. Int. J. Antimicrob. Agents 33, 490-491.

Johansen, H. K., Moskowitz, S. M., Ciofu, O., Pressler, T., and Hoiby, N. (2008). Spread of colistin resistant nonmucoid Pseudomonas aeruginosa among chronically infected Danish cystic fibrosis patients. J. Cyst. Fibros. 7, 391-397.

Jones, R. N. (1998). Important and emerging $\beta$-lactamase-mediated resistances in hospital-based pathogens: the Amp C enzymes. Diagn. Microbiol. Infect. Dis. 31, 461-466.

Jones, R. N., Stilwell, M. G., Rhomberg, P. R., and Sader, H. S. (2009). Antipseudomonal activity of piperacillin/tazobactam: more than a decade of experience from the SENTRY Antimicrobial Surveillance Program (1997-2007). Diagn. Microbiol. Infect. Dis. 65, 331-334.

Juan, C., Macia, M. D., Gutierrez, O., Vidal, C., Perez, J. L., and Oliver, A. (2005). Molecular mechanisms of $\beta$-lactam resistance mediated by AmpC hyperproduction in Pseudomonas aeruginosa clinical strains. Antimicrob. Agents Chemother. 49, 4733-4738.

Juan, C., Mulet, X., Zamorano, L., Alberti, S., Perez, J. L., and Oliver, A. (2009). Detection of the novel extendedspectrum $\beta$-lactamase OXA-161 from a plasmid-located integron in Pseudomonas aeruginosa clinical isolates from Spain. Antimicrob. Agents Chemother. 53, 5288-5290.

Kallen, A. J., Hidron, A. I., Patel, J., and Srinivasan, A. (2010). Multidrug resistance among Gram-negative pathogens that caused healthcareassociated infections reported to the National Healthcare Safety Network, 2006-2008. Infect. Control Hosp. Epidemiol. 31, 528-531.

Keen, E. F., III, Robinson, B. J., Hospenthal, D. R., Aldous, W. K., Wolf, S.E., Chung, K. K., and Murray, C. K. (2010). Prevalence of multidrug-resistant organisms recovered at a military burn center. Burns 36, 819-825.

Kerr, K. G., and Snelling, A. M. (2009). Pseudomonas aeruginosa: a formidable and ever-present adversary. J. Hosp. Infect. 73, 338-344.

Kettner, M., Milosovic, P., Hletkova, M., and Kallova, J. (1995). Incidence and mechanisms of aminoglycoside resistance in Pseudomonas aeruginosa serotype $\mathrm{O} 11$ isolates. Infection 23 380-383.

Kim, J. Y., Park, Y. J., Kwon, H. J., Han, K., Kang, M. W., and Woo, G. J. (2008). Occurrence and mechanisms of amikacin resistance and its association with $\beta$-lactamases in Pseudomonas aeruginosa: a Korean nationwide study. J. Antimicrob. Chemother. 62, 479-483.

Kiser, T. H., Obritsch, M. D., Jung, R., Maclaren, R., and Fish, D. N. (2010). Efflux pump contribution to multidrug resistance in clinical isolates of Pseudomonas aeruginosa. Pharmacotherapy 30, 632-638.

Köhler, T., Epp, S. F., Curty, L. K., and Pechére, J.-C. (1999). Characterization of MexT, the regulator of the MexEMexF-OprN multidrug efflux system of Pseudomonas aeruginosa. J. Bacteriol. 181, 6300-6305.

Köhler, T., Michea-Hamzehpour, M., Henze, U., Gotoh, N., Curty, L. K., and Pechere, J.-C. (1997). Characterization of MexE-MexF-OprN, a positively regulated multidrug efflux system of Pseudomonas aeruginosa. Mol. Microbiol. 23, 345-354.

Kong, K. F., Jayawardena, S. R., Del Puerto, A., Wiehlmann, L., Laabs, U., Tummler, B., and Mathee, K. (2005). Characterization of poxB, a chromosomal-encoded Pseudomonas aeruginosa oxacillinase. Gene 358, 82-92.

Kotsakis, S. D., Papagiannitsis, C. C., Tzelepi, E., Legakis, N. J., Miriagou, V., and Tzouvelekis, L. S. (2010). GES-13, a $\beta$-lactamase variant possessing Lys-104 and Asn-170 in Pseudomonas aeruginosa. Antimicrob. Agents Chemother. 54, 1331-1333.

Labuschagne, C. J., Weldhagen, G. F., Ehlers, M.M., and Dove, M. G. (2008). Emergence of class 1 integron-associated GES-5 and GES-5-like extendedspectrum $\beta$-lactamases in clinical isolates of Pseudomonas aeruginosa in South Africa. Int. J. Antimicrob. Agents 31, 527-530.

Lambert, M. L., Suetens, C., Savey, A., Palomar, M., Hiesmayr, M., Morales, I., Agodi, A., Frank, U., Mertens, K., Schumacher, M., and Wolkewitz, M. (2011). Clinical outcomes of healthcare-associated infections and antimicrobial resistance in patients admitted to European intensive-care units: a cohort study. Lancet Infect. Dis. 11, 30-38.

Landman, D., Bratu, S., Alam, M., and Quale, J. (2005). Citywide emergence of Pseudomonas aeruginosa strains with reduced susceptibility to polymyxin B. J. Antimicrob. Chemother. 55, 954-957.

Lee, J. K., Lee, Y. S., Park, Y. K., and Kim, B. S. (2005). Alterations in the GyrA and GyrB subunits of topoisomerase II and the ParC and ParE subunits of topoisomerase IV in ciprofloxacin-resistant clinical isolates of Pseudomonas aeruginosa. Int. J. Antimicrob. Agents 25, 290-295.

Lewis, K. (2008). Multidrug tolerance of biofilms and persister cells. Curr. Top. Microbiol. Immunol. 322, 107-131.

Li, H., Toleman, M. A., Bennett, P. M., Jones, R. N., and Walsh, T. R. (2008). Complete Sequence of p07-406, a 24,179-base-pair plasmid harboring the $b l a_{\mathrm{VIM}-7}$ metallo- $\beta$-lactamase gene in a Pseudomonas aeruginosa isolate from the United States. Antimicrob. Agents Chemother. 52, 3099-3105.

Li, X. Z., and Nikaido, H. (2009). Effluxmediated drug resistance in bacteria: an update. Drugs 69, 1555-1623. 
Libisch, B., Poirel, L., Lepsanovic, Z., Mirovic, V., Balogh, B., Paszti, J., Hunyadi, Z., Dobak, A., Fuzi, M., and Nordmann, P. (2008). Identification of PER-1 extended-spectrum $\beta$-lactamase producing Pseudomonas aeruginosa clinical isolates of the international clonal complex CC11 from Hungary and Serbia. FEMS Immunol. Med. Microbiol. 54, 330-338.

Lincopan, N., Neves, P., Mamizuka, E. M., and Levy, C.E. (2010). Balanoposthitis caused by Pseudomonas aeruginosa coproducing metallo- $\beta$-lactamase and $16 \mathrm{~S}$ rRNA methylase in children with hematological malignancies. Int. J. Infect. Dis. 14, e344-e347.

Lister, P. D., Wolter, D. J., and Hanson, N. D. (2009). Antibacterial-resistant Pseudomonas aeruginosa: clinical impact and complex regulation of chromosomally encoded resistance mechanisms. Clin. Microbiol. Rev. 22, 582-610.

Liu, W., Liu, X., Liao, J., Zhang, Y., and Liang, X. (2010). Identification of bla OXA-128 and bla OXA-129, two novel OXA-type extended-spectrum$\beta$-lactamases in Pseudomonas aeruginosa, in Hunan Province, China. J. Basic Microbiol. 50(Suppl. 1), S116-S119.

Livermore, D. M. (1991). $\beta$-lactamases of Pseudomonas aeruginosa. Antibiot. Chemother. 44, 215-220.

Livermore, D. M. (1992). Interplay of impermeability and chromosomal $\beta$-lactamase activity in imipenemresistant Pseudomonas aeruginosa. Antimicrob. Agents Chemother. 36, 2046-2048.

Livermore, D. M. (1995). $\beta$-lactamases in laboratory and clinical resistance. Clin. Microbiol. Rev. 8, 557-584.

Livermore, D. M., and Yang, Y. J. (1987). $\beta$-lactamase lability and inducer power of newer $\beta$-lactam antibiotics in relation to their activity against $\beta$-lactamase-inducibility mutants of Pseudomonas aeruginosa. J. Infect. Dis. 155, 775-782.

Lodge, J. M., Minchin, S. D., Piddock, L. J., and Busby, J. W. (1990). Cloning, sequencing and analysis of the structural gene and regulatory region of the Pseudomonas aeruginosa chromosomal ampC $\beta$-lactamase. Biochem. J. 272, 627-631.

Lopez, D., Vlamakis, H., and Kolter, R. (2010). Biofilms. Cold Spring Harb. Perspect. Biol. 2, a000398.

Macfarlane, E. L., Kwasnicka, A., and Hancock, R. E. (2000). Role of Pseudomonas aeruginosa PhoP-phoQ in resistance to antimicrobial cationic peptides and aminoglycosides. Microbiology 146, 2543-2554.

Macia, M. D., Blanquer, D., Togores, B., Sauleda, J., Perez, J. L., and Oliver, A.
(2005). Hypermutation is a key factor in development of multiple-antimicrobial resistance in Pseudomonas aeruginosa strains causing chronic lung infections. Antimicrob. Agents Chemother. 49, 3382-3386.

MacLeod, D. L., Nelson, L. E., Shawar, R. M., Lin, B. B., Lockwood, L. G., Dirk, J. E., Miller, G. H., Burns, J. L., and Garber, R. L. (2000). Aminoglycosideresistance mechanisms for cystic fibrosis Pseudomonas aeruginosa isolates are unchanged by long-term, intermittent, inhaled tobramycin treatment. J. Infect. Dis. 181, 1180-1184.

Mah, T. F., Pitts, B., Pellock, B., Walker, G. C., Stewart, P. S., and O’Toole, G. A. (2003). A genetic basis for Pseudomonas aeruginosa biofilm antibiotic resistance. Nature 426, 306-310.

Mahar, P., Padiglione, A. A., Cleland, H., Paul, E., Hinrichs, M., and Wasiak, J. (2010). Pseudomonas aeruginosa bacteraemia in burns patients: risk factors and outcomes. Burns 36, 1228-1233.

Mandsberg, L. F., Ciofu, O., Kirkby, N., Christiansen, L. E., Poulsen, H. E., and Hoiby, N. (2009). Antibiotic resistance in Pseudomonas aeruginosa strains with increased mutation frequency due to inactivation of the DNA oxidative repair system. Antimicrob. Agents Chemother. 53, 2483-2491.

Maniati, M., Ikonomidis, A., Mantzana, P., Daponte, A., Maniatis, A. N., and Pournaras, S. (2007). A highly carbapenem-resistant Pseudomonas aeruginosa isolate with a novel $b l a_{\mathrm{VIM}-4 /}$ blaP1b integron overexpresses two efflux pumps and lacks OprD. J. Antimicrob. Chemother. 60, 132-135.

Mansour, W., Dahmen, S., Poirel, L., Charfi, K., Bettaieb, D., Boujaafar, N., and Bouallegue, O. (2009). Emergence of SHV-2a extended-spectrum $\beta$-lactamases in clinical isolates of Pseudomonas aeruginosa in a university hospital in Tunisia. Microb. Drug Resist. 15, 295-301.

Maseda, H., Saito, K., Nakajima, A., and Nakae, T. (2000). Variation of the mexT gene, a regulator of the MexEF-oprN efflux pump expression in wild-type strains of Pseudomonas aeruginosa.FEMS Microbiol. Lett. 192, 107-112.

Masuda, N., Sakagawa, E., Ohya, S., Gotoh, N., Tsujimoto, H., and Nishino, T. (2000). Substrate specificities of MexAB-OprM, MexCD-OprJ, and MexXY-OprM efflux pumps in Pseudomonas aeruginosa. Antimicrob. Agents Chemother. 44, 3322-3327.

Matsuo, Y., Eda, S., Gotoh, N., Yoshihara, E., and Nakae, T. (2004). MexZmediated regulation of mexXY multidrug efflux pump expression in
Pseudomonas aeruginosa by binding on the mexZ-mexX intergenic DNA. FEMS Microbiol. Lett. 238, 23-28.

Matthaiou, D. K., Michalopoulos, A., Rafailidis, P. I., Karageorgopoulos, D. E., Papaioannou, V., Ntani, G., Samonis, G., and Falagas, M. E. (2008). Risk factors associated with the isolation of colistin-resistant Gram-negative bacteria: a matched case-control study. Crit. Care Med. 36, 807-811.

Mauldin, P. D., Salgado, C. D., Hansen, I. S., Durup, D. T., and Bosso, J. A. (2010). Attributable hospital cost and length of stay associated with health care-associated infections caused by antibiotic-resistant Gramnegative bacteria. Antimicrob. Agents Chemother. 54, 109-115.

McPhee, J. B., Lewenza, S., and Hancock, R. E. (2003). Cationic antimicrobial peptides activate a two-component regulatory system, PmrA-PmrB, that regulates resistance to polymyxin $B$ and cationic antimicrobial peptides in Pseudomonas aeruginosa. Mol. Microbiol. 50, 205-217.

Mendes, R.E., Toleman, M. A., Ribeiro, J., Sader, H. S., Jones, R. N., and Walsh, T. R. (2004). Integron carrying a novel metallo- $\beta$-lactamase gene, bla $^{\mathrm{IMP}-16}$, and a fused form of aminoglycoside-resistant gene aac $\left(6^{\prime}\right)-30$ / aac $\left(6^{\prime}\right)-\mathrm{Ib}^{\prime}$ : report from the SENTRY Antimicrobial Surveillance Program. Antimicrob. Agents Chemother. 48, 4693-4702.

Miller, G. H., Sabatelli, F. J., Naples, L., Hare, R. S., and Shaw, K. J. (1994). Resistance to aminoglycosides in Pseudomonas. Aminoglycoside Resistance Study Groups. Trends Microbiol. 2, 347-353.

Molina, J., Cordero, E., and Pachon, J. (2009). New information about the polymyxin/colistin class of antibiotics. Expert Opin. Pharmacother. 10, 2811-2828.

Montero, M., Horcajada, J. P., Sorli, L., Alvarez-Lerma, F., Grau, S., Riu, M., Sala, M., and Knobel, H. (2009). Effectiveness and safety of colistin for the treatment of multidrug-resistant Pseudomonas aeruginosa infections. Infection 37, 461-465.

Morero, N. R., and Argarana, C. E. (2009). Pseudomonas aeruginosa deficient in 8-oxodeoxyguanine repair system shows a high frequency of resistance to ciprofloxacin. FEMS Microbiol. Lett. 290, 217-226.

Morita, Y., Cao, L., Gould, G., Avison, M. B., and Poole, K. (2006). nalD encodes a second repressor of the mexABoprM multidrug efflux operon of Pseudomonas aeruginosa. J. Bacteriol. 188, 8649-8654.
Moskowitz, S. M., Ernst, R. K., and Miller, S. I. (2004). PmrAB, a two-component regulatory system of Pseudomonas aeruginosa that modulates resistance to cationic antimicrobial peptides and addition of aminoarabinose to lipid A. J. Bacteriol. 186, 575-579.

Mulcahy, L. R., Burns, J. L., Lory, S., and Lewis, K. (2010). Emergence of Pseudomonas aeruginosa strains producing high levels of persister cells in patients with cystic fibrosis. $J$. Bacteriol. 192, 6191-6199.

Mulet, X., Macia, M. D., Mena, A., Juan, C., Perez, J. L., and Oliver, A. (2009). Azithromycin in Pseudomonas aeruginosa biofilms: bactericidal activity and selection of nfxB mutants. Antimicrob. Agents Chemother. 53, 1552-1560.

Muller, C., Plesiat, P., and Jeannot, K. (2010). A two-component regulatory system interconnects resistance to polymyxins, aminoglycosides, fluoroquinolones, and $\beta$-lactams in Pseudomonas aeruginosa. Antimicrob. Agents Chemother. 55, 1211-1221.

Muramatsu, H., Horii, T., Takeshita, A., Hashimoto, H., and Maekawa, M. (2005). Characterization of fluoroquinolone and carbapenem susceptibilities in clinical isolates of levofloxacin-resistant Pseudomonas aeruginosa. Chemotherapy 51, 70-75.

Mutlu, G. M., and Wunderink, R. G. (2006). Severe pseudomonal infections. Curr. Opin. Crit. Care 12, 458-463.

Naas, T., Aubert, D., Lambert, T., and Nordmann, P. (2006). Complex genetic structures with repeated elements, a sul-type class 1 integron, and the blaVEB extended-spectrum $\beta$-lactamase gene. Antimicrob. Agents Chemother. 50, 1745-1752.

Nakano, M., Deguchi, T., Kawamura, T., Yasuda, M., Kimura, M., Okano, Y., and Kawada, Y. (1997). Mutations in the gyrA and parC genes in fluoroquinolone-resistant clinical isolates of Pseudomonas aeruginosa. Antimicrob. Agents Chemother. 41, 2289-2291.

Nordmann, P., and Mammeri, H. (2007). Extended-spectrum cephalosporinases: structure, detection and epidemiology. Future Microbiol. 2, 297-307.

Ochs, M. M., McCusker, M. P., Bains, M., and Hancock, R. E. (1999). Negative regulation of the Pseudomonas aeruginosa outer membrane porin OprD selective for imipenem and basic amino acids. Antimicrob. Agents Chemother. 43, 1085-1090.

Okamoto, K., Gotoh, N., and Nishino, T. (2002). Alterations of susceptibility of Pseudomonas aeruginosa by overproduction of multidrug efflux systems, MexAB-OprM, MexCD-OprJ, and MexXY/OprM to carbapenems: 
substrate specificities of the efflux systems. J. Infect. Chemother. 8, 371-373. Oliver, A. (2010). Mutators in cystic fibrosis chronic lung infection: prevalence, mechanisms, and consequences for antimicrobial therapy. Int. J. Med. Microbiol. 300, 563-572.

Oliver, A., Baquero, F., and Blazquez, J. (2002). The mismatch repair system (mutS, mutL and uvrD genes) in Pseudomonas aeruginosa: molecular characterization of naturally occurring mutants. Mol. Microbiol. 43, 1641-1650.

Oliver,A., Canton, R., Campo, P., Baquero, F., and Blazquez, J. (2000). High frequency of hypermutable Pseudomonas aeruginosa in cystic fibrosis lung infection. Science 288, 1251-1254.

Oliver, A., and Mena, A. (2010). Bacterial hypermutation in cystic fibrosis, not only for antibiotic resistance. Clin. Microbiol. Infect. 16, 798-808.

Page, M. G., and Heim, J. (2009). Prospects for the next anti-Pseudomonas drug. Curr. Opin. Pharmacol. 9, 558-565.

Pai, H., Kim, J., Kim, J., Lee, J. H., Choe, K. W., and Gotoh, N. (2001). Carbapenem resistance mechanisms in Pseudomonas aeruginosa clinical isolates. Antimicrob. Agents Chemother. $45,480-484$.

Pamp, S. J., Gjermansen, M., Johansen, H. K., and Tolker-Nielsen, T. (2008). Tolerance to the antimicrobial peptide colistin in Pseudomonas aeruginosa biofilms is linked to metabolically active cells, and depends on the pmr and mexAB-oprM genes. Mol. Microbiol. 68, 223-240.

Paterson, D. L. (2006). The epidemiological profile of infections with multidrug-resistant $P$ seudomonas aeruginosa and Acinetobacter species. Clin. Infect. Dis. 43(Suppl. 2), S43-S48.

Paterson, D. L., and Bonomo, R. A. (2005). Extended-spectrum $\beta$-lactamases: a clinical update. Clin. Microbiol. Rev. 18, 657-686.

Paul, M., Yahav, D., Bivas, A., Fraser, A., and Leibovici, L. (2010). Antipseudomonal $\beta$-lactams for the initial, empirical, treatment of febrile neutropenia: comparison of $\beta$-lactams. Cochrane Database Syst. Rev. 11, CD005197.

Pena, C., Suarez, C., Tubau, F., Juan, C., Moya, B., Dominguez, M. A., Oliver, A., Pujol, M., and Ariza, J. (2009). Nosocomial outbreak of a noncefepime-susceptible ceftazidimesusceptible Pseudomonas aeruginosa strain overexpressing MexXY-OprM and producing an integron-borne PSE-1 $\beta$-lactamase. J. Clin. Microbiol. 47, 2381-2387.

Pfeifer,Y., Cullik, A., and Witte, W. (2010). Resistance to cephalosporins and carbapenems in Gram-negative bacterial pathogens. Int. J. Med. Microbiol. 300, 371-379.

Picao, R. C., Poirel, L., Gales, A. C., and Nordmann, P. (2009a). Diversity of $\beta$-lactamases produced by ceftazidime-resistant Pseudomonas aeruginosa isolates causing bloodstream infections in Brazil. Antimicrob. Agents Chemother. 53, 3908-3913.

Picao, R. C., Poirel, L., Gales, A. C., and Nordmann, P. (2009b). Further identification of CTX-M-2 extended-spectrum $\beta$-lactamase in Pseudomonas aeruginosa. Antimicrob. Agents Chemother. 53, 2225-2226.

Poirel, L., Brinas, L., Verlinde, A., Ide, L., and Nordmann, P. (2005). BEL1 , a novel clavulanic acid-inhibited extended-spectrum $\beta$-lactamase, and the class 1 integron In 120 in Pseudomonas aeruginosa. Antimicrob. Agents Chemother. 49, 3743-3748.

Poirel, L., Docquier, J. D., De Luca, F., Verlinde, A., Ide, L., Rossolini, G. M., and Nordmann, P. (2010a). BEL-2, an extended-spectrum $\beta$-lactamase with increased activity toward expanded-spectrum cephalosporins in Pseudomonas aeruginosa. Antimicrob. Agents Chemother. 54, 533-535.

Poirel, L., Naas, T., and Nordmann, P. (2010b). Diversity, epidemiology, and genetics of class $\mathrm{D} \beta$-lactamases. Antimicrob. Agents Chemother. 54, 24-38.

Poirel, L., Nordmann, P., Lagrutta, E., Cleary, T., and Munoz-Price, L. S. (2010c). Emergence of KPCproducing Pseudomonas aeruginosa in the United States. Antimicrob. Agents Chemother. 54, 3072.

Poirel, L., Lambert, T., Turkoglu, S., Ronco, E., Gaillard, J., and Nordmann, P. (2001). Characterization of Class 1 integrons from Pseudomonas aeruginosa that contain the $b l a_{\mathrm{VIM}-2}$ carbapenem-hydrolyzing $\beta$-lactamase gene and of two novel aminoglycoside resistance gene cassettes. Antimicrob. Agents Chemother. 45, 546-552.

Poirel, L., Magalhaes, M., Lopes, M., and Nordmann, P. (2004). Molecular analysis of metallo- $\beta$-lactamase gene $b l a_{\mathrm{SPM}-1}$-surrounding sequences from disseminated Pseudomonas aeruginosa isolates in Recife, Brazil. Antimicrob. Agents Chemother. 48, 1406-1409.

Poirel, L., and Nordmann, P. (2002). Acquired carbapenem-hydrolyzing $\beta$-lactamases and their genetic support. Curr. Pharm. Biotechnol. 3 , 117-127.

Poole, K. (2000). Efflux-mediated resistance to fluoroquinolones in Gramnegative bacteria. Antimicrob. Agents Chemother. 44, 2233-2241.
Poole, K. (2002). Outer membranes and efflux: the path to multidrug resistance in Gram-negative bacteria. Curr Pharm. Biotechnol. 3, 77-98.

Poole, K. (2004a). "Efflux pumps," in Pseudomonas, Vol. 1. Genomics, life style and molecular architecture, ed. J. L. Ramos (New York, NY: Kluwer Academic, Plenum Publishers), 635-674.

Poole, K. (2004b). Resistance to $\beta$-lactam antibiotics. Cell. Mol. Life Sci. 61, 2200-2223.

Poole, K. (2005). Aminoglycoside resistance in Pseudomonas aeruginosa. Antimicrob. Agents Chemother. 49 , 479-487.

Poole, K. (2007). Efflux pumps as antimicrobial resistance mechanisms. Ann. Med. 39, 162-176.

Poole, K., Gotoh, N., Tsujimoto, H., Zhao, Q., Wada, A., Yamasaki, T., Neshat, S., Yamagishi, J.-I., Li, X.-Z., and Nishino, T. (1996). Overexpression of the mexC-mex-oprJ efflux operon in $n f x B$ multidrug resistant strains of Pseudomonas aeruginosa. Mol. Microbiol. 21, 713-724.

Pournaras, S., Maniati, M., Spanakis, N., Ikonomidis, A., Tassios, P. T., Tsakris, A., Legakis, N. J., and Maniatis, A. N (2005). Spread of efflux pump-overexpressing, non-metallo- $\beta$-lactamaseproducing, meropenem-resistant but ceftazidime-susceptible Pseudomona aeruginosa in a region with $b l a_{\text {VIM }}$ endemicity. J. Antimicrob. Chemother. 56, 761-764.

Quale, J., Bratu, S., Gupta, J., and Landman, D. (2006). Interplay of efflux system, $a m p C$, and oprD expression in carbapenem resistance of Pseudomonas aeruginosa clinical isolates. Antimicrob. Agents Chemother. 50, 1633-1641.

Queenan, A. M., and Bush, K. (2007). Carbapenemases: the versatile $\beta$-lactamases. Clin. Microbiol. Rev. $20,440-458$.

Queenan, A. M., Shang, W., Bush, K., and Flamm, R. K. (2010). Differential selection of single-step AmpC or efflux mutants of Pseudomonas aeruginosa by using cefepime, ceftazidime, or ceftobiprole. Antimicrob. Agents Chemother. 54, 4092-4097.

Ramirez, M. S., and Tolmasky, M. E. (2010). Aminoglycoside modifying enzymes. Drug Resist. 13, 151-171.

Reinhardt, A., Kohler, T., Wood, P., Rohner, P., Dumas, J. L., Ricou, B., and Van Delden, C. (2007). Development and persistence of antimicrobial resistance in Pseudomonas aeruginosa: a longitudinal observation in mechanically ventilated patients. Antimicrob. Agents Chemother. 51, 1341-1350.
Rejiba, S., Aubry, A., Petitfrere, S. Jarlier, V., and Cambau, E. (2008). Contribution of parE mutation and efflux to ciprofloxacin resistance in Pseudomonas aeruginosa clinical isolates. J. Chemother. 20, 749-752.

Riccio, M. L., Pallecchi, L., Fontana, R., and Rossolini, G. M. (2001). In70 of plasmid pAX22, a bla ${ }_{\mathrm{VIM}-1}$-containing integron carrying a new aminoglycoside phosphotransferase gene cassette. Antimicrob. Agents Chemother. 45, 1249-1253.

Rodriguez-Martinez, J.M., Poirel, L., and Nordmann, P. (2009a). Extendedspectrum cephalosporinases in Pseudomonas aeruginosa. Antimicrob. Agents Chemother. 53, 1766-1771.

Rodriguez-Martinez, J. M., Poirel, L., and Nordmann, P. (2009b). Molecular epidemiology and mechanisms of carbapenem resistance in Pseudomonas aeruginosa. Antimicrob. Agents Chemother. 53, 4783-4788.

Rossolini, G. M., and Mantengoli, E. (2005). Treatment and control of severe infections caused by multiresistant Pseudomonas aeruginosa. Clin. Microbiol. Infect. 11(Suppl. 4), 17-32.

Sabtcheva, S., Galimand, M., Gerbaud, G., Courvalin, P., and Lambert, T. (2003). Aminoglycoside resistance gene ant (4')-IIb of Pseudomonas aeruginosa BM4492, a clinical isolate from Bulgaria. Antimicrob. Agents Chemother. 47, 1584-1588.

Sader, H. S., Reis, A. O., Silbert, S., and Gales, A. C. (2005). IMPs, VIMs and SPMs: the diversity of metallo- $\beta$ lactamases produced by carbapenemresistant Pseudomonas aeruginosa in a Brazilian hospital. Clin. Microbiol. Infect. 11, 73-76.

Sadovskaya, I., Vinogradov, E., Li, J., Hachani, A., Kowalska, K., and Filloux, A. (2010). High-level antibiotic resistance in Pseudomonas aeruginosa biofilm: the $n d v B$ gene is involved in the production of highly glycerol-phosphorylated $\beta$-(1->3)-glucans, which bind aminoglycosides. Glycobiology 20, 895-904.

Sakurai, Y., Yoshida, Y., Saitoh, K., Nemoto, M., Yamaguchi, A., and Sawai, T. (1990). Characteristics of aztreonam as a substrate, inhibitor and inducer for $\beta$-lactamases. J. Antibiot. 43, 403-410.

Salabi, A. E., Toleman, M. A., Weeks, J., Bruderer, T., Frei, R., and Walsh, T. R (2010). First report of the metallo$\beta$-lactamase SPM-1 in Europe. Antimicrob. Agents Chemother. 54, 582.

Samonis, G., Matthaiou, D. K., Kofteridis, D., Maraki, S., and Falagas, M. E. (2010). In vitro susceptibility to various antibiotics of colistin-resistant Gram-negative bacterial isolates in 
a general tertiary hospital in Crete, Greece. Clin. Infect.Dis. 50, 1689-1691.

Schobert, M., and Tielen, P. (2010). Contribution of oxygen-limiting conditions to persistent infection in Pseudomonas aeruginosa. Future Microbiol. 5, 603-621.

Schwartz, T., Volkmann, H., Kirchen, S., Kohnen, W., Schon-Holz, K., Jansen, B., and Obst, U. (2006). Real-time PCR detection of Pseudomonas aeruginosa in clinical and municipal wastewater and genotyping of the ciprofloxacinresistant isolates. FEMS Microbiol. Ecol. 57, 158-167.

Shahcheraghi, F., Nikbin, V. S., and Feizabadi, M. M. (2009). Prevalence of ESBLs genes among multidrugresistant isolates of Pseudomonas aeruginosa isolated from patients in Tehran. Microb. Drug Resist. 15, 37-39.

Shahid, M., and Malik, A. (2005). Resistance due to aminoglycoside modifying enzymes in Pseudomonas aeruginosa isolates from burns patients. Indian J. Med. Res. 122, 324-329.

Shaw, K. J., Munayyer, H., Rather, P. N., Hare, R. S., and Miller, G. H. (1993). Nucleotide sequence analysis and DNA hybridization studies of the ant $\left(4^{\prime}\right)$-IIa gene from Pseudomonas aeruginosa. Antimicrob. Agents Chemother. 37, 708-714.

Shawar, R. M., MacLeod, D. L., Garber, R. L., Burns, J. L., Stapp, J. R., Clausen, C. R., and Tanaka, S. K. (1999). Activities of tobramycin and six other antibiotics against Pseudomonas aeruginosa isolates from patients with cystic fibrosis. Antimicrob. Agents Chemother. 43, 2877-2880.

Shorr, A. F. (2009). Review of studies of the impact on Gram-negative bacterial resistance on outcomes in the intensive care unit. Crit. Care Med. 37, 1463-1469.

Slama, T. G. (2008). Gram-negative antibiotic resistance: there is a price to pay. Crit. Care 12(Suppl. 4), S4.

Smith, E. E., Buckley, D. G., Wu, Z., Saenphimmachak, C., Hoffman, L. R., D'Argenio, D. A., Miller, S. I., Ramsey, B. W., Speert, D. P., Moskowitz, S. M., Burns, J. L., Kaul, R., and Olson, M. V. (2006). Genetic adaptation by Pseudomonas aeruginosa to the airways of cystic fibrosis patients. Proc. Natl. Acad. Sci U. S. A. 103, 8487-8492.

Sobel, M. L., McKay, G. A., and Poole, K. (2003). Contribution of the MexXY multidrug transporter to aminoglycoside resistance in Pseudomonas aeruginosa clinical isolates. Antimicrob. Agents Chemother. 47, 3202-3207.

Sobel, M. L., Poole, K., and Neshat, S. (2005). Mutations in PA2491
(mexS) promote MexT-dependent mexEF-oprN expression and multidrug resistance in a clinical strain of Pseudomonas aeruginosa. J. Bacteriol. 187, 1246-1253.

Srikumar, R., Paul, C. J., and Poole, K. (2000). Influence of mutations in the $m e x R$ repressor gene on expression of the MexA-MexB-OprM multidrug efflux system of Pseudomonas aeruginosa. J. Bacteriol. 182, 1410-1414.

Strateva, T., Ouzounova-Raykova, V., Markova, B., Todorova, A., MartevaProevska, Y., and Mitov, I. (2007). Widespread detection of VEB-1-type extended-spectrum $\beta$-lactamases among nosocomial ceftazidime-resistant Pseudomonas aeruginosa isolates in Sofia, Bulgaria. J. Chemother. 19, 140-145.

Strateva, T., and Yordanov, D. (2009). Pseudomonas aeruginosa - a phenomenon of bacterial resistance. J. Med. Microbiol. 58, 1133-1148.

Taccetti, G., Campana, S., Neri, A.S., Boni, V., and Festini, F. (2008). Antibiotic therapy against Pseudomonas aeruginosa in cystic fibrosis. J. Chemother. 20, 166-169.

Talbot, G. H., Bradley, J., Edwards, J. E. Jr., Gilbert, D., Scheld, M., and Bartlett, J. G. (2006). Bad bugs need drugs: an update on the development pipeline from the Antimicrobial Availability Task Force of the Infectious Diseases Society of America. Clin. Infect. Dis. 42, 657-668.

Tam, V. H., Chang, K. T., Abdelraouf, K., Brioso, C. G., Ameka, M., McCaskey, L. A., Weston, J. S., Caeiro, J. P., and Garey, K.W. (2010). Prevalence, resistance mechanisms, and susceptibility of multidrug-resistant bloodstream isolates of Pseudomonas aeruginosa. Antimicrob. Agents Chemother. 54, 1160-1164.

Tam, V. H., Schilling, A. N., LaRocco, M. T., Gentry, L. O., Lolans, K., Quinn, J. P., and Garey, K. W. (2007). Prevalence of AmpC over-expression in bloodstream isolates of Pseudomonas aeruginosa. Clin. Microbiol. Infect. 13, 413-418.

Toleman, M. A., Rolston, K., Jones, R. N., and Walsh, T. R. (2003). Molecular and biochemical characterization of OXA-45, an extended-spectrum class $2 \mathrm{~d}^{\prime} \beta$-lactamase in Pseudomonas aeruginosa. Antimicrob. Agents Chemother. 47, 2859-2863.

Tomas, M., Doumith, M., Warner, M., Turton, J. F., Beceiro, A., Bou, G., Livermore, D. M., and Woodford, N. (2010). Efflux pumps, OprD porin, AmpC $\beta$-lactamase, and multiresistance in Pseudomonas aeruginosa isolates from cystic fibrosis patients. Antimicrob. Agents Chemother. 54, 2219-2224.
Trias, J., and Nikaido, H. (1990). Outer membrane protein D2 catalyzes facilitated diffusion of carbapenems and penems through the outer membrane of Pseudomonas aeruginosa. Antimicrob. Agents Chemother. 34, 52-57.

Tumbarello, M., Repetto, E., Trecarichi, E. M., Bernardini, C., DE Pascale, G., Parisini, A., Rossi, M., Molinari, M. P., Spanu, T., Viscoli, C., Cauda, R., and Bassetti, M. (2011). Multidrugresistant Pseudomonas aeruginosa bloodstream infections: risk factors and mortality. Epidemiol. Infect. (in press).

Upadhyay, S., Sen, M. R., and Bhattacharjee, A. (2010). Presence of different $\beta$-lactamase classes among clinical isolates of Pseudomonas aeruginosa expressing AmpC $\beta$-lactamase enzyme. J. Infect. Dev. Ctries. 4, 239-242.

Veesenmeyer, J. L., Hauser, A. R., Lisboa, T., and Rello, J. (2009). Pseudomonas aeruginosa virulence and therapy: evolving translational strategies. Crit. Care Med. 37, 1777-1786.

Vettoretti, L., Floret, N., Hocquet, D., Dehecq, B., Plesiat, P., Talon, D., and Bertrand, X. (2009). Emergence of extensive-drug-resistant Pseudomonas aeruginosa in a French university hospital. Eur. J. Clin. Microbiol. Infect. Dis. 28, 1217-1222.

Viedma, E., Juan, C., Acosta, J., Zamorano, L., Otero, J. R., Sanz, F., Chaves, F., and Oliver, A. (2009). Nosocomial spread of colistin-only-sensitive sequence type 235 Pseudomonas aeruginosa isolates producing the extendedspectrum $\beta$-lactamases GES- 1 and GES-5 in Spain. Antimicrob. Agents Chemother. 53, 4930-4933.

Villegas, M. V., Lolans, K., Correa, A., Kattan, J. N., Lopez, J. A., and Quinn, J. P. (2007). First identification of Pseudomonas aeruginosa isolates producing a KPC-type carbapenemhydrolyzing $\beta$-lactamase. Antimicrob. Agents Chemother. 51, 1553-1555.

Wagner, V. E., and Iglewski, B. H. (2008). $P$. aeruginosa biofilms in $C F$ infection. Clin. Rev. Allergy Immunol. 35, 124-134.

Waine, D. J., Honeybourne, D., Smith, E. G., Whitehouse, J. L., and Dowson, C. G. (2008). Association between hypermutator phenotype, clinical variables, mucoid phenotype, and antimicrobial resistance in Pseudomonas aeruginosa. J. Clin. Microbiol. 46, 3491-3493.

Walsh, T. R. (2010). Emerging carbapenemases: a global perspective. Int. J. Antimicrob. Agents 36(Suppl. 3), S8-S14.

Walsh, T. R., Toleman, M. A., Poirel, L., and Nordmann, P. (2005). Metallo- $\beta$ - lactamases: the quiet before the storm? Clin. Microbiol. Rev. 18, 306-325.

Walther-Rasmussen, J., and Hoiby, N. (2007). Class A carbapenemases. J. Antimicrob. Chemother. 60, 470-482.

Wang, J., Zhou, J. Y., Qu, T. T., Shen, P., Wei, Z. Q., Yu, Y. S., and Li, L. J. (2010). Molecular epidemiology and mechanisms of carbapenem resistance in Pseudomonas aeruginosa isolates from Chinese hospitals. Int. J. Antimicrob. Agents 35, 486-491.

Werner, E., Roe, F., Bugnicourt, A., Franklin, M. J., Heydorn, A., Molin, S., Pitts, B., and Stewart, P. S. (2004). Stratified growth in Pseudomonas aeruginosa biofilms. Appl. Environ. Microbiol. 70, 6188-6196.

Wolter, D. J., Khalaf, N., Robledo, I. E., Vazquez, G. J., Sante, M. I., Aquino, E. E., Goering, R. V., and Hanson, N. D. (2009a). Surveillance of carbapenemresistant Pseudomonas aeruginosa isolates from Puerto Rican Medical Center Hospitals: dissemination of KPC and IMP-18 $\beta$-lactamases. Antimicrob. Agents Chemother. 53, 1660-1664.

Wolter, D. J., Kurpiel, P. M., Woodford, N., Palepou, M. F., Goering, R. V., and Hanson, N. D. (2009b). Phenotypic and enzymatic comparative analysis of the novel KPC variant KPC-5 and its evolutionary variants, KPC-2 and KPC-4. Antimicrob. Agents Chemother. 53, 557-562.

Wolter, D. J., Smith-Moland, E., Goering, R. V., Hanson, N. D., and Lister, P. D. (2004). Multidrug resistance associated with mexXY expression in clinical isolates of Pseudomonas aeruginosa from a Texas hospital. Diagn. Microbiol. Infect. Dis. 50, 43-50.

Woodford, N., Zhang, J., Kaufmann, M. E., Yarde, S., Tomas, M. M., Faris, C., Vardhan, M. S., Dawson, S., Cotterill, S. L., and Livermore, D. M. (2008). Detection of Pseudomonas aeruginosa isolates producing VEB-type extended-spectrum $\beta$-lactamases in the United Kingdom. J. Antimicrob. Chemother. 62, 1265-1268.

Wright, A., Hawkins, C. H., Anggard, E. E., and Harper, D. R. (2009). A controlled clinical trial of a therapeutic bacteriophage preparation in chronic otitis due to antibioticresistant Pseudomonas aeruginosa; a preliminary report of efficacy. Clin. Otolaryngol. 34, 349-357.

Xavier, D. E., Picao, R. C., Girardello, R., Fehlberg, L. C., and Gales, A. C. (2010). Efflux pumps expression and its association with porin downregulation and $\beta$-lactamase production among Pseudomonas aeruginosa causing bloodstream infections in 
Brazil. BMC Microbiol. 10, 217. doi: 10.1186/1471-2180-10-217

Yamane, K., Doi, Y., Yokoyama, K., Yagi, T., Kurokawa, H., Shibata, N., Shibayama, K., Kato, H., and Arakawa, Y. (2004). Genetic environments of the rmtA gene in Pseudomonas aeruginosa clinical isolates. Antimicrob. Agents Chemother. 48, 2069-2074.

Zavascki, A. P., Goldani, L. Z., Li, J., and Nation, R. L. (2007). Polymyxin $\mathrm{B}$ for the treatment of multidrugresistant pathogens: a critical review. J. Antimicrob. Chemother. 60, 1206-1215.

Zhanel, G. G., Decorby, M., Adam, H., Mulvey, M. R., McCracken, M., LagaceWiens, P., Nichol, K. A., Wierzbowski, A., Baudry, P. J., Tailor, F., Karlowsky, J. A., Walkty, A., Schweizer, F., Johnson, J., and Hoban, D. J. (2010). Prevalence of antimicrobial-resistant pathogens in canadian hospitals: results of the Canadian Ward Surveillance Study (CANWARD 2008). Antimicrob. Agents Chemother. 54, 4684-4693.

Zhanel, G. G., Hoban, D. J., Schurek, K., and Karlowsky, J. A. (2004). Role of efflux mechanisms on fluoroquinolone resistance in Streptococcus pneumoniae and Pseudomonas aeruginosa. Int. J. Antimicrob. Agents 24, 529-535.

Zhang, L., and Mah, T. F. (2008) Involvement of a novel efflux system in biofilm-specific resistance to antibiotics. J. Bacteriol. 190, 4447-4452.

Zhao, W.H., Chen, G., Ito, R., and Hu, Z.Q. (2009). Relevance of resistance levels to carbapenems and integron-borne $b l a_{\mathrm{IMP}-1}, b l a_{\mathrm{IMP}-7}, b l a_{\mathrm{IMP}-10}$ and $b l a_{\mathrm{VIM}-2}$ in clinical isolates of Pseudomonas aeruginosa. J. Med. Microbiol. 58, 1080-1085.
Zhao, W. H., and Hu, Z. Q. (2010). $\beta$-lactamases identified in clinical isolates of Pseudomonas aeruginosa. Crit. Rev. Microbiol. 36, 245-258.

Zhou, Y., Yu, H., Guo, Q., Xu, X., Ye, X., Wu, S., Guo, Y., and Wang, M. (2010). Distribution of $16 \mathrm{~S}$ rRNA methylases among different species of Gramnegative bacilli with high-level resistance to aminoglycosides. Eur. J. Clin. Microbiol. Infect. Dis. 29, 1349-1353.

Zilberberg, M. D., Chen, J., Mody, S. H., Ramsey, A. M., and Shorr, A. F. (2010). Imipenem resistance of Pseudomonas in pneumonia: a systematic literature review. BMC Pulm. Med. 10, 45. doi: 10.1186/1471-2466-10-45

Conflict of Interest Statement: The author declares that the research was conducted in the absence of any commercial or financial relationships that could be construed as a potential conflict of interest.

Received: 28 January 2011; paper pending published: 18 March 2011; accepted: 24 March 2011; published online: 05 April 2011.

Citation: Poole K (2011) Pseudomonas aeruginosa: resistance to the max. Front. Microbio. 2:65. doi: 10.3389/ fmicb.2011.00065

This article was submitted to Frontiers in Cellular and Infection Microbiology, a specialty of Frontiers in Microbiology. Copyright (c) 2011 Poole. This is an openaccess article subject to a non-exclusive license between the authors and Frontiers Media SA, which permits use, distribution and reproduction in other forums, provided the original authors and source are credited and other Frontiers condition are complied with. 